\title{
Functions, mechanisms, and therapeutic implications of METTL14 in human cancer
}

\author{
Qian Guan ${ }^{1,2+}$, Huiran Lin $^{3 \dagger}$, Lei Miao ${ }^{1 \dagger}$, Huiqin Guo ${ }^{1,2}$, Yongping Chen ${ }^{1}$, Zhenjian Zhuo ${ }^{1,4^{*}}$ and Jing He ${ }^{1 *}$ (D)
}

\begin{abstract}
RNA modification plays a crucial role in many biological functions, and its abnormal regulation is associated with the progression of cancer. Among them, $\mathrm{N}^{6}$-methyladenine $\left(\mathrm{m}^{6} \mathrm{~A}\right)$ is the most abundant RNA modification. Methyltransferase-like 14 (METTL14) is the central component of the $\mathrm{m}^{6} \mathrm{~A}$ methylated transferase complex, which is involved in the dynamic reversible process of $\mathrm{m}^{6} \mathrm{~A}$ modification. METTL 14 acts as both an oncogene and tumor suppressor gene to regulate the occurrence and development of various cancers. The abnormal $\mathrm{m}^{6} \mathrm{~A}$ level induced by METTL14 is related to tumorigenesis, proliferation, metastasis, and invasion. To date, the molecular mechanism of METTL14 in various malignant tumors has not been fully studied. In this paper, we systematically summarize the latest research progress on METTL14 as a new biomarker for cancer diagnosis and its biological function in human tumors and discuss its potential clinical application. This study aims to provide new ideas for targeted therapy and improved prognoses in cancer.
\end{abstract}

Keywords: RNA modification, $\mathrm{m}^{6} \mathrm{~A}, \mathrm{METTL} 14$, Cancer, Drug discovery

\section{Introduction}

Among posttranscriptional modifications, more than 100 different types of RNA chemical modifications have been identified. $\mathrm{N}^{6}$-methyladenosine $\left(\mathrm{m}^{6} \mathrm{~A}\right)$ modifications account for approximately $50 \%$ of all methylated RNA [1] and are one of the most common and abundant internal modifications [2,3]. It is found in almost all eukaryotes and in some bacteria, viruses, yeasts, and plants [4, 5]. In 1974, the presence of a methyl substituent at N-6 of adenosine in nucleic acids was first identified in purified poly (A) RNA fragments [6, 7]. Subsequent studies confirmed that it is mainly present in the RRACH motif (where $\mathrm{R}=\mathrm{A} / \mathrm{G}, \mathrm{H}=\mathrm{A} / \mathrm{C} / \mathrm{U}$ ) and is enriched in the 3'

\footnotetext{
*Correspondence: zhenjianzhuo@163.com; hejing198374@gmail.com ${ }^{\dagger}$ Qian Guan, Huiran Lin and Lei Miao contributed equally to this work 1 Department of Pediatric Surgery, Guangzhou Institute of Pediatrics, Guangdong Provincial Key Laboratory of Research in Structural Birth Defect Disease, Guangzhou Women and Children's Medical Center, Guangzhou Medical University, 9 Jinsui Road, Guangzhou 510623, Guangdong, China

Full list of author information is available at the end of the article
}

untranslated regions (UTRs), near the stop codon, and in the internal exon.

$\mathrm{m}^{6} \mathrm{~A}$ methylation is widely present in mRNA, miRNAs, and long noncoding RNAs [8-11] and is involved in the basic pathophysiological metabolic processes of RNA, including splicing, nuclear output, translation, decay, folding, and RNA-protein interactions [12-15]. This newly identified type of modification plays an important role in regulating gene expression, which has become known as RNA epigenetics. In human physiology, $\mathrm{m}^{6} \mathrm{~A}$ methylation plays a critical role in embryonic stem cell differentiation, meiosis, DNA repair, circadian rhythm, tissue development, and tumorigenesis [16-19]. Abnormalities in $\mathrm{m}^{6} \mathrm{~A}$ methylation result in embryonic development disorders, failure of differentiation, neurological diseases, and tumorigenesis [20-23].

Functionally, $\mathrm{m}^{6} \mathrm{~A}$ is divided into "writer" $[24,25]$, "eraser" [26], and "reader" [27] (Table 1, Fig. 1). $\mathrm{m}^{6} \mathrm{~A}$ modification is a dynamically reversible pathway that mainly relies on erasers to encode $\mathrm{m}^{6} \mathrm{~A}$ demethylase and remove $\mathrm{m}^{6} \mathrm{~A}$ modifications in RNA molecules. At present, the known erasing genes include FTO and

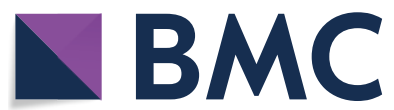

(c) The Author(s) 2022. Open Access This article is licensed under a Creative Commons Attribution 4.0 International License, which permits use, sharing, adaptation, distribution and reproduction in any medium or format, as long as you give appropriate credit to the original author(s) and the source, provide a link to the Creative Commons licence, and indicate if changes were made. The images or other third party material in this article are included in the article's Creative Commons licence, unless indicated otherwise in a credit line to the material. If material is not included in the article's Creative Commons licence and your intended use is not permitted by statutory regulation or exceeds the permitted use, you will need to obtain permission directly from the copyright holder. To view a copy of this licence, visit http://creativecommons.org/licenses/by/4.0/. The Creative Commons Public Domain Dedication waiver (http://creativeco mmons.org/publicdomain/zero/1.0/) applies to the data made available in this article, unless otherwise stated in a credit line to the data. 
Table 1 The functions of $m^{6} A$ enzymes in RNA metabolism

\begin{tabular}{|c|c|c|}
\hline Type & Factors & Function \\
\hline \multirow[t]{9}{*}{ Writers } & METTL3 & Catalyzes $\mathrm{m}^{6} \mathrm{~A}$ modification [52] \\
\hline & METTL14 & Stabilizes the structure of MTC and recognizes target RNAs [68] \\
\hline & WTAP & Contributes to the localization of METTL3-METTL14 heterodimer to the nuclear speckle $[49,70]$ \\
\hline & VIRMA & $\begin{array}{l}\text { Recruits the MTC to the special RNA site and interacts with polyadenylation cleavage factors } \\
\text { CPSF5 and CPSF6 [51] }\end{array}$ \\
\hline & BM15/15B & Recruits METTL3-METTL14 heterodimer to target transcripts [53] \\
\hline & ZC3H13 & Bridges WTAP to the mRNA-binding factor Nito [55] \\
\hline & $\mathrm{ZCCHC4}$ & Responsible for $\mathrm{m}^{6} \mathrm{~A}$ modification of $28 \mathrm{~S}$ rRNA [60-62] \\
\hline & METTL16 & Catalyzes $\mathrm{m}^{6} \mathrm{~A}$ modification in U6-snRNA and participates in pre-RNA splicing $[56,57]$ \\
\hline & METTL5 & Responsible for $\mathrm{m}^{6} \mathrm{~A}$ modification of $18 \mathrm{~S}$ rRNA $[58,59]$ \\
\hline \multirow[t]{3}{*}{ Erasers } & FTO & Removes $\mathrm{m}^{6} \mathrm{~A}$ modification [29-31] \\
\hline & ALKBH5 & Removes $\mathrm{m}^{6} \mathrm{~A}$ modification $[31,58,110]$ \\
\hline & $\mathrm{ALKBH} 3$ & Removes $\mathrm{m}^{6} \mathrm{~A}$ modification $[33,34]$ \\
\hline \multirow[t]{8}{*}{ Readers } & YTHDC1 & Impacts mRNA splicing and nuclear export [37] \\
\hline & YTHDC2 & Promotes RNA decay and translation [38] \\
\hline & YTHDF1 & Enhances the translational rates of its mRNA targets [35] \\
\hline & YTHDF2 & Induces mRNA degradation [36] \\
\hline & YTHDF3 & Promotes mRNA translation (YTHDF1) and decay (YTHDF2) [39] \\
\hline & IGF2BP1/2/3 & Promotes mRNA stability and translation [41] \\
\hline & HNRNPA2B1/C/G & Regulates primary miRNA processing, mRNA structure and alternative splicing $[44,45]$ \\
\hline & elF3 & Promotes mRNA translation [42] \\
\hline
\end{tabular}

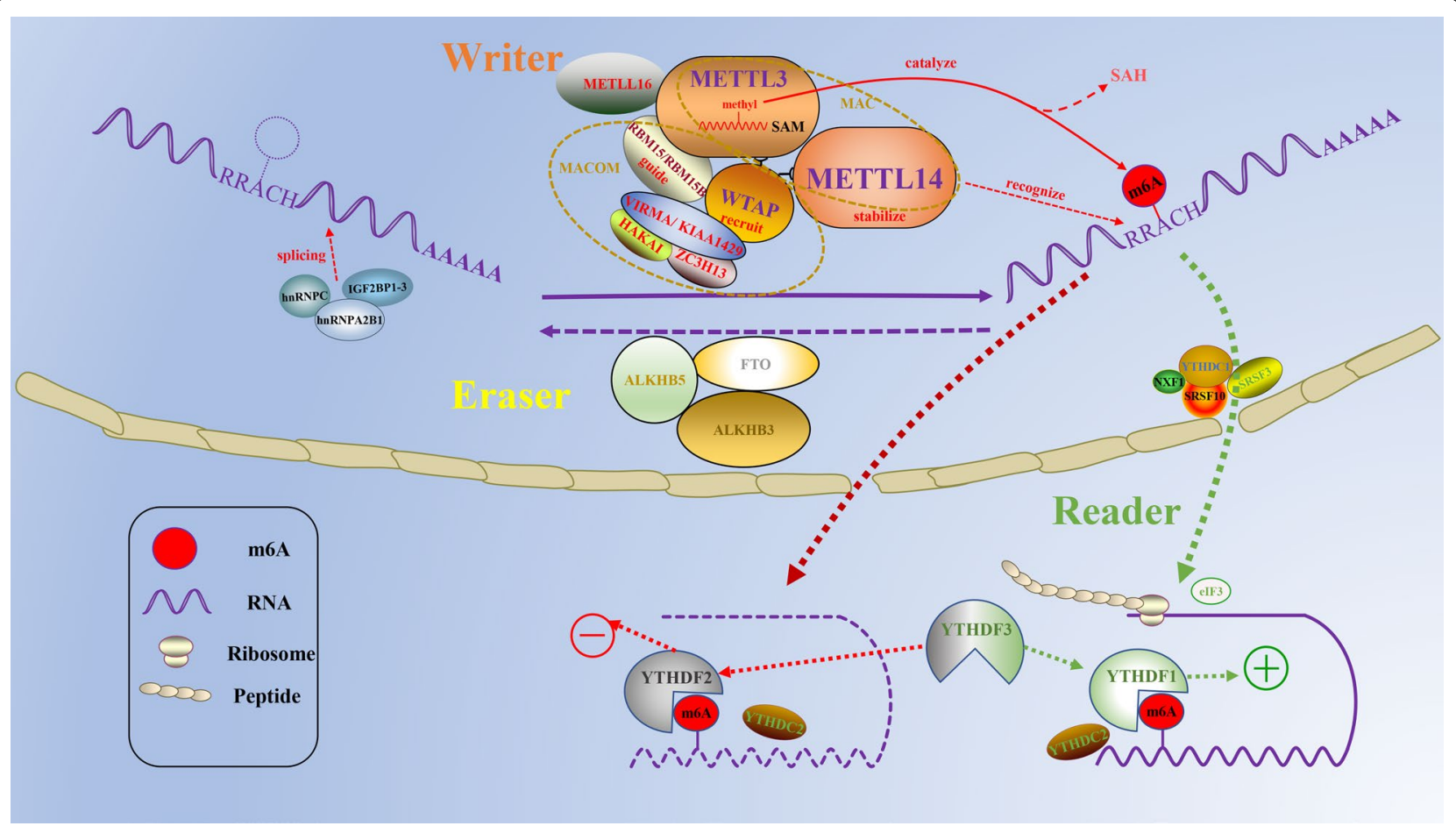

Fig. 1 Molecular composition of the $m^{6} A$ RNA methylation. $m^{6} A$ is installed by "writers" (METTL3/14, WTAP, RBM15/15B, VIRMA, HAKAI, ZC3H13, METTL5/16, and ZCCHC4), removed by "erasers" (FTO, ALKBH5, and ALKBH3), and recognized by"readers" (YTHDC1/2, YTHDF1/2/3, IGF2BP1/2/3, HNRNPA2B1/C/G, and elF3) 
ALKBH5 [28]. FTO can affect the splicing and stability of mRNA by regulating $\mathrm{m}^{6} \mathrm{~A}$ modification $[29,30]$, while ALKBH5-mediated demethylation affects the output and metabolism of mRNA and the assembly of mRNA processing factors in nuclear spots [31]. Both of these genes have dual regulatory effects on the occurrence and development of tumors. They catalyze the conversion of $\mathrm{m}^{6} \mathrm{~A}$ to N6-hydroxymethyladenosine $\left(\mathrm{hm}^{6} \mathrm{~A}\right)$ and $\mathrm{hm}^{6} \mathrm{~A}$ to N6-formyladenosine (f6A) in two steps. Once formed, f6A spontaneously transforms into adenosine (A) [32]. In recent years, another demethylation transferase, AlkB homolog 3 (ALKBH3), has been identified, which may have a similar process $[33,34]$. The $\mathrm{m}^{6} \mathrm{~A}$ "reader" is responsible for identifying $\mathrm{m}^{6} \mathrm{~A}$ methylated transcripts and generating functional signals, including the YTH domain family of proteins (YTHDC1/2, YTHDF1/2/3) [35-39], IGF2 mRNA binding protein (IGF2BP1/2/3) [40, 41], eukaryotic initiation factor 3 (eIF3) [42], and the heterokaryotic nuclear RNA protein family (HNRNPC, HNRNPG) [43-45]. These readers have been shown to mediate RNA splicing, nuclear export, translation efficiency, RNA stability, and RNA decay [37]. Different reading proteins recognize different $\mathrm{m}^{6} \mathrm{~A}$ sites and perform different functions [46]. For example, YTHDF1/YTHDF3 identifies the $\mathrm{m}^{6} \mathrm{~A}$ sequence in the ITGA6 3' UTR and promotes the translation of target genes that affect the malignant progression of bladder cancer [47]. YTHDF2 recognizes the methylation of SOCS2 and promotes its mRNA degradation to further regulate $\mathrm{HCC}$ cell proliferation and migration [48]. Methylation of RNA molecules is catalyzed by the methyltransferase complex (MTC), known as the "writer" protein, which consists of METTL3, METTL14, Wilms tumor 1 associated protein (WTAP), RNA-binding motif protein 15/15B (RBM15/15B), zinc finger $\mathrm{CCCH}$-type containing 13 (ZC3H13) proteins, Vir-like $\mathrm{m}^{6} \mathrm{~A}$ methyltransferase-associated (VIRMA/KIAA1429), and Cbl proto-oncogene like1 (CBLL1/Hakai) [49-53]. METTL3 is the only methyltransferase with catalytic activity, but it needs to bind to METTL14 to be effective [54]. The two combine to form a core complex (also known as the $\mathrm{m}^{6} \mathrm{~A}$-METTL complex, MAC) that catalyzes $\mathrm{m}^{6} \mathrm{~A}$ methylation of most RNA. Other components of MTC form regulatory complexes (also known as $\mathrm{m}^{6} \mathrm{~A}-\mathrm{METTL}$ associated complexes, MACOM) that direct the core complex to specific site regions of RNA and provide binding sites, leading to increased catalytic activity $[50,55]$. In addition, several studies have demonstrated the novel readers METTL16, METTL5, and ZCCHC4, which mediate $\mathrm{m}^{6} \mathrm{~A}$ modifications of U6 snRNA, 18S rRNA, and 28S rRNA, respectively [56-62]. "Writers" and "erasers" can effectively install and remove mRNA methylation, and they work together to achieve a stable, dynamically balanced reversible process [63]. After the completion of the methylated splicing modification, the mature mRNA will undergo nuclear export and recognition by the reading protein, leading to further functional realization $[64,65]$.

Although METTL14 does not have true catalytic activity, it serves as an important adapter for METTL3 activity to enhance methyltransferase activity by recognizing RNA substrates and methyl localization [66-68]. As an allosteric activator of METTL3 activity, METTL14, as an inactivated methyltransferase and allosteric activator of METTL3 activity, is involved in the development of various tumors. When METTL14 is mutated at cancer-associated sites, this reduces the catalytic activity and substrate specificity of the enzymes involved, leading to the reversal of methylation efficiency of consensus GGACU and non-consensus GGAUU sequences (decreased methylation at consensus sites and increased methylation at non-consensus sites), resulting in the occurrence of cancer [66, 69]. This paper reviews the research progress in understanding the role of METTL14 in the molecular mechanism of various malignant tumors and the biological processes involving METTL14. In addition, we discuss the structure and function of the METTL3-METTL14 heterodimer, the association of METTL14 with histone modification and potential therapeutic strategies for the dysregulation mechanisms of METTL14.

\section{Structure and function of the METTL3-METTL14 heterodimer}

METTL3 and METTL14 are essential components of the methyltransferases complex, which form a stable heterodimer in a 1:1 ratio [69]. Both of them contain the methyltransferase domain (MTD) [70]. MTD3 is comprised of 357-580 AA residues, which includes three loops (gate loop 1, gate loop 2, and interface loop), two $\mathrm{CCCH}$ motifs, catalytic sites (DPPW motif), and S-adenosylmethionine (SAM) binding sites [54, 70, 71]. Among these, SAM binding sites are mainly contained in loop 1 and loop 2, while the remaining rings, namely, the interface rings, have a large area and extensive contact with the METTL14 MTD [54]. METTL3 can transfer SAM methyl groups to the adenine base of RNA to produce homocysteine (SAH) to achieve methyl transfer [70]. In addition, its catalytic cavity has only the conservative motif EPPL [70]. Although MTD14 is structurally similar to MTD3, it lacks SAM binding sites, and thus it does not have catalytic activity [71]. However, METTL3 alone has weak catalytic activity, which is greatly increased only when combined with METTL14 [72]. Some studies have explained this phenomenon, suggesting that METTL14 provides an RNA-binding scaffold that plays an important role in maintaining the structural integrity of binary 
complexes and recognizing RNA substrates [73]. It is worth noting that some studies have reported that the C-terminal RGG domain of METTL14 contributes to its recognition function [74]. However, these studies are not sufficient. We still do not understand the mechanism by which this structure helps to identify targets, and whether there are other structures that help in this identification. If there are, it is of interest to know what are they and how they interact. In addition, it has been found in recent years that the METTL3-METTL14 complex has a certain repair effect on DNA damaged regions in vitro [75]. Under the same conditions, the METTL3METTL14 heterodimer ssDNA methylation rate is much higher than that of ssRNA, and the single-stranded DNA has catalytic activity, while the double-stranded DNA does not [76]. This result provides new knowledge about the METTL3-METTL14 complex (Fig. 2).

\section{METTL14 functions as an antioncogene}

In most tumors, METTL14 acts as an antioncogene, downregulating the level of $\mathrm{m}^{6} \mathrm{~A}$ in tumor cells by exerting its function as a $\mathrm{m}^{6} \mathrm{~A}$ methyltransferase to suppress the occurrence and progression of tumors (Fig. 3).

\section{Colorectal cancer}

Colorectal cancer (CRC) is a malignant disease with a high incidence worldwide. According to statistics, there are 945,000 new cases and nearly 700,000 deaths every year, making it one of the top four causes of cancer death [77-79]. Liu et al. confirmed that METTL14 expression was upregulated in CRC tissues, and survival analysis showed that the METTL14 expression level was significantly correlated with the prognosis of CRC [80]. Chen et al. further found that downregulation of METTL14 and $\mathrm{m}^{6} \mathrm{~A}$ promoted the growth, invasion, and migration of cancer cells. The specific molecular mechanism is that overexpression of METTL14 affects the binding of DGCR8 and primiR-375 and regulates the level of miR-375. Furthermore, it further downregulates Yes-associated protein 1 (YAP1) to inhibit the growth of cancer cells and inhibit the invasion and migration of cancer cells by downregulating SP1 [81]. To better understand how METTL14 inhibits the malignant progression of cancer cells, some studies have also included reading proteins. For example, Wang et al. showed that methyl-CpG binding protein 2 (MeCP2) and METTL14 enhance the expression of Kruppel like factor 4 (KLF4) protein and mRNA in an IGF2BP2-dependent manner

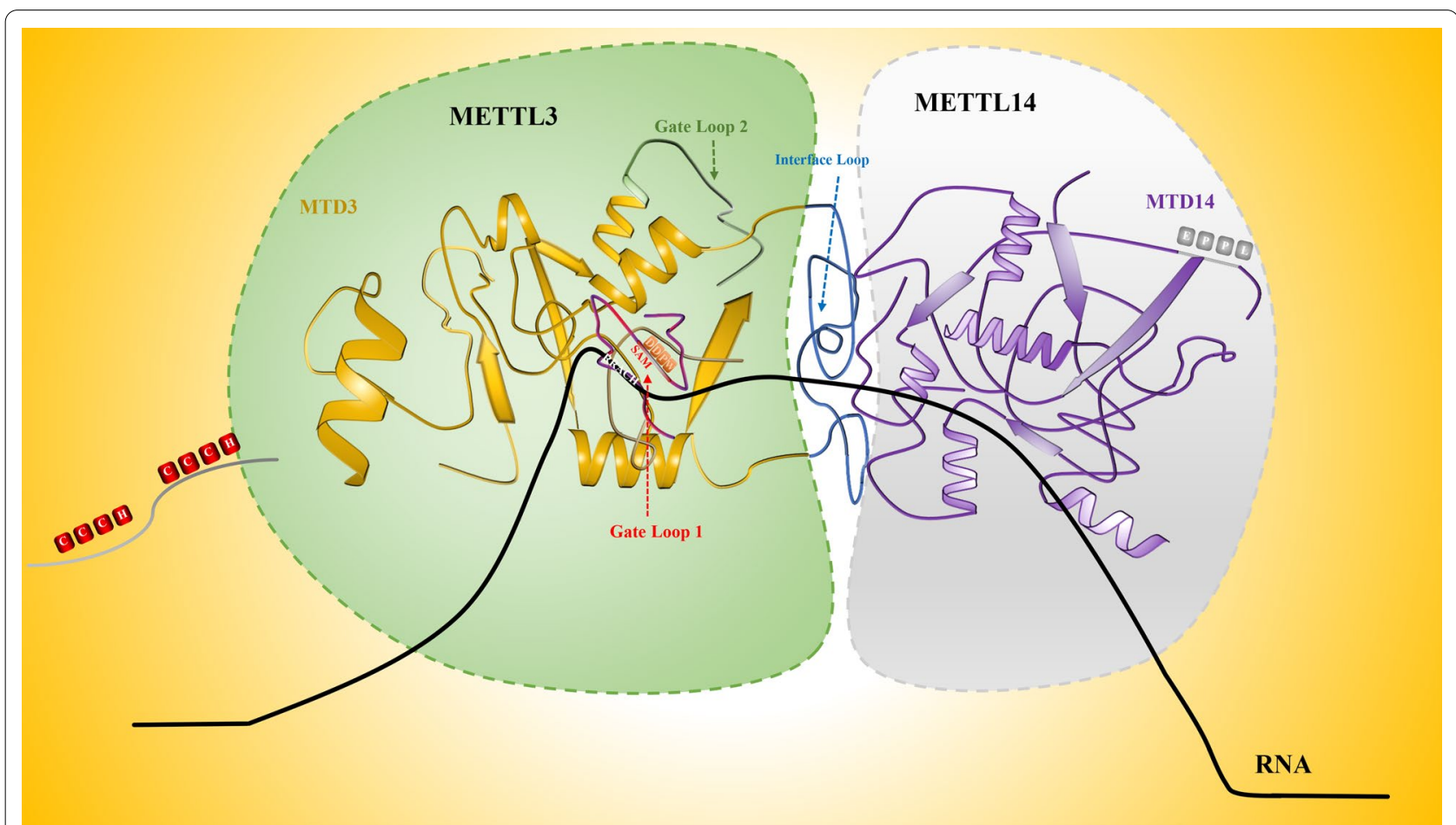

Fig. 2 The METTL3-MEETL14 methyltransferase complex. MTD3 of METTL3 is the real catalyst, while METTL14 stabilizes the structure and promotes RNA substrate recognition to improve methylation transferase activity. The catalytic cavity of METTL3 (DPPW motif) has an open conformation and binds to a cofactor (SAM), and METTL14 (EPPL motif) assumes a closed conformation. The two CCCH (ZnF) moieties of METTL3 are required for RNA substrate binding 


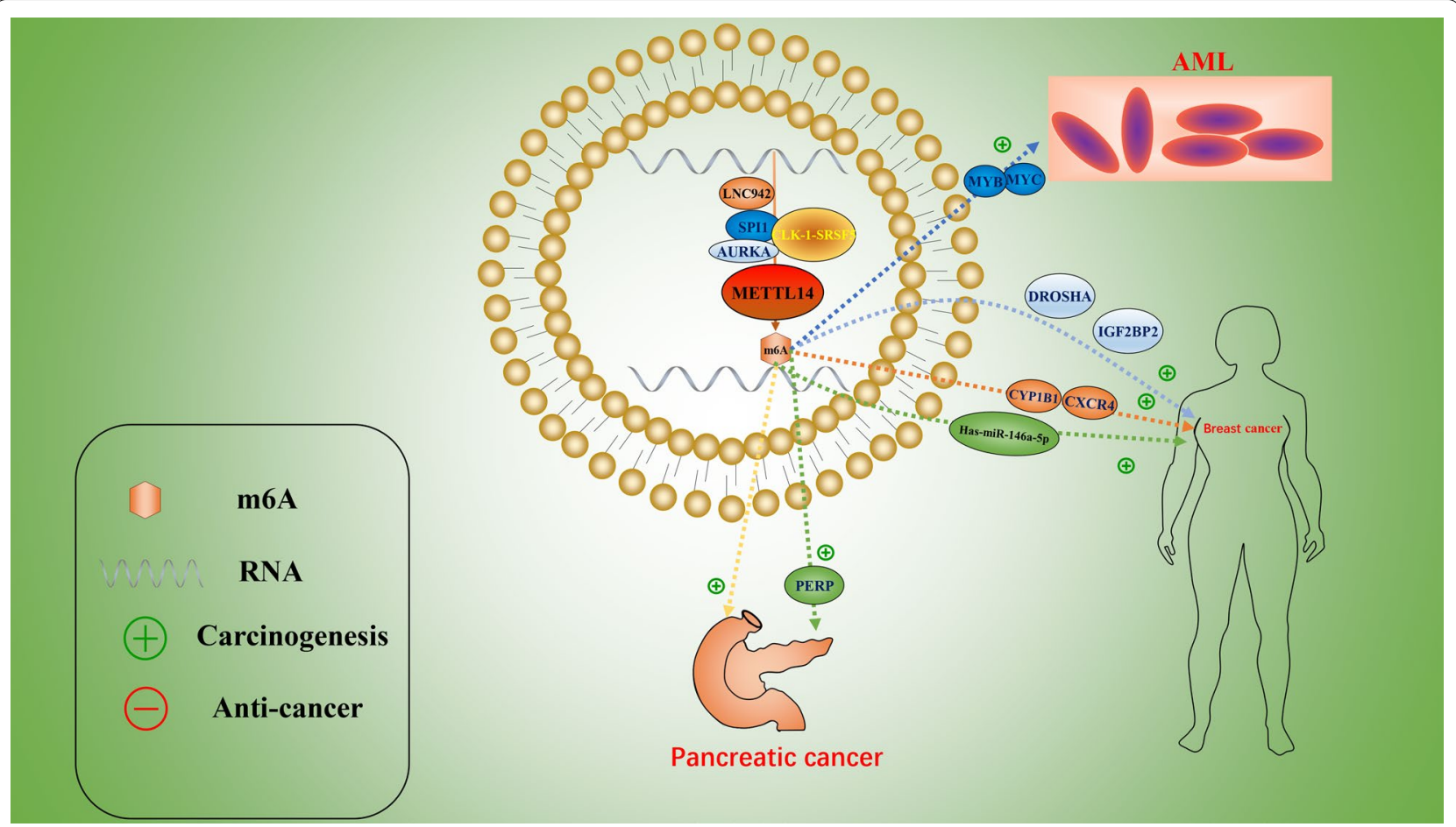

Fig. 3 The stimulatory role of METTL14 in human cancers, including AML, breast cancer, and pancreatic cancer

and inhibit the proliferation, metastasis, and invasion of CRC [82]. Chen et al. also confirmed that METTL14 mediates epithelial-mesenchymal transformation (EMT) and that PI3K/AKT signal transduction inhibition of CRC cell migration and invasion works partly through SRY-related high-mobility-group box 4 (SOX4). When METTL14 is knocked down, SOX4 mRNA is increased, and this process depends on YTHDF2 recognition [83]. Another study proved that lncRNA XIST was the downstream target gene of METTL14 through transcriptomic sequencing (RNA-seq) and methylated RNA immunoprecipitation (Me-RIP). When METTL14 was knocked down, the $\mathrm{m}^{6} \mathrm{~A}$ level of XIST was downregulated and mRNA expression increased, thus promoting the malignant progression of CRC. In addition, METTL14 downregulates XIST-dependent $\mathrm{m}^{6} \mathrm{~A}-\mathrm{YTHDF} 2$ pathways [84]. Significant downregulation of METTL14 and YTHDC2 may be a potential prognostic biomarker for rectal cancer [85]. Moreover, Dong et al. revealed that in tumorassociated macrophages (TAMs) of CRC, knockout of METTL14 results in a decrease in $\mathrm{m}^{6} \mathrm{~A}$ levels, an increase in EBI3, and dysfunction of antitumor $\mathrm{T}$ cells, which then promots the malignant progression of tumors [86]. In conclusion, studies have shown that the relationship between METTL14 and CRC is relatively extensive and involves the immune microenvironment. It is worth mentioning that studies that examine the METTL14 gene in the context of the immune system represent an interesting direction.

\section{Liver cancer}

Hepatocellular carcinoma (HCC) is a highly malignant tumor with high recurrence and metastasis rates and poor mortality. It is the most common fatal malignant tumor worldwide [87-89]. Although the risk indicators for HCC are well understood, the underlying molecular mechanisms remain unclear. Traditionally, it is believed that the occurrence of liver cancer is related to chromosome gain/loss and somatic mutation. In recent years, increasing evidence has shown that epigenetics plays a vital role in regulating the occurrence of liver cancer [90]. Shi et al. showed that METTL14 gene expression was significantly downregulated in HCC, which was associated with a poor prognosis in cancer patients. EGFR was identified as the downstream target gene of METTL14 by RNA sequencing and $\mathrm{m}^{6} \mathrm{~A}$ sequencing, and METTL14 was shown to regulate the EGFR/PI3K/AKT signaling pathway in an $\mathrm{m}^{6} \mathrm{~A}$ methylation-dependent manner, thereby inhibiting EMT and invasion of cancer cells [91]. However, in metastatic liver cancer, miR-126 is the target gene of METL14, and this pathway downregulates the expression of miR-126 to promote tumor metastasis by regulating the interaction between DGCR8 and primiR-126 [92]. $\mathrm{Du}$ et al. found that METTL14-mediated $\mathrm{m}^{6} \mathrm{~A}$ 
modification maintained the stability of USP48 mRNA, thus participating in the regulation of $\mathrm{HCC}$, and revealed that the METTL14-USP48-SIRT6 axis plays an inhibitory role by regulating glycolysis [93]. In addition, Li et al. proposed that METTL14 may inhibit the occurrence of HCC by upregulating the expression levels of cysteine sulfonate decarboxylase (CSAD), glutamic oxalacetic transaminase (GOT2), and cytokine signaling inhibitor 2 (SOCS2) [94]. These studies show that METTL14 has a significant impact on liver cancer.

\section{Breast cancer}

Breast cancer remains a serious challenge for women around the world, with a five-year survival rate of less than $30 \%$ for patients with advanced cancer [95]. Further research on the molecular mechanism of breast cancer is becoming increasingly important to improve the survival rate and clinical prognosis. Several studies have demonstrated reduced METTL14 expression in breast cancer tissues $[96,97]$. Its expression level was shown to be negatively correlated with tumor grade [98]. The lower the expression level was, the worse the prognosis [97]. Overexpression of METTL14 can lead to a decrease in $\mathrm{m}^{6} \mathrm{~A}$ levels and inhibit the migration and proliferation of cancer cells [96].

\section{Endometrial carcinoma}

Endometrial cancer (EC) is a common malignant gynecological tumor worldwide. Even in early-stage cancer, routine surgery has a great impact on the fertility of patients, and the development of effective interventions is of great importance $[99,100]$. Ma et al. reported that $\mathrm{m}^{6} \mathrm{~A}$ RNA methylation was closely associated with the clinicopathological stage and prognosis of endometrial cancer and that METTL14 was used as a potential marker for the diagnosis and prognosis of endometrial cancer [101]. Liu et al. found that the R298P mutation in the key component of METTL14 leads to a reduction in $\mathrm{m}^{6} \mathrm{~A}$ methylation and activation of the AKT pathway, thereby promoting the proliferation and migration of endometrial cancer cells. The increase in AKT activity depended on the decrease in PHLPP2 expression and the increase in mTORC2 expression [102].

\section{Bladder cancer}

Bladder cancer (BC) is the most universal tumor of the urinary system and has become the fifth most common cancer in the United States, producing an estimated 81,400 cases in 2019 [22, 103]. Gu et al. found that low expression of METT14 in BC and bladder tumor-initiating cells (TICs), decreased $\mathrm{m}^{6} \mathrm{~A}$ levels, and $\mathrm{m}^{6} \mathrm{~A}$ levels were associated with clinical severity and prognosis. Knockout of METTL14 enhances Notch1 expression and stability, promoting the development of $\mathrm{BC}$ and bladder TIC self-renewal [104]. The METTL14- $\mathrm{m}^{6} \mathrm{~A}-\mathrm{Notch} 1$ pathway plays a critical role in bladder tumorigenesis and bladder TICs. Zhang et al. revealed that isorhapontigenin (ISO) inhibited the migration, invasion, and EMT of BC cells by upregulating METTL14 mRNA expression and decreasing vimentin protein levels by activating the transcription factor FOXO3a [105].

\section{Neuroblastoma}

Neuroblastoma (NB) is the most common tumor in infants and young children. It originates from the sympathetic ganglion and bilateral adrenal glands and has the highest morbidity and mortality in infancy $[106,107]$. Wang et al. proposed that METTL14 combined with WTAP, HNRNPC, YTHDF1, and IGF2BP2 contributed to the prognosis of $\mathrm{NB}$ and could be used as new targets for clinical treatment [107]. Our group first found that some SNPs in the METTL14 gene were closely associated with the risk of neuroblastoma. METTL14 gene rs298982 G>A and rs62328061 A $>$ G were significantly associated with reduced susceptibility to neuroblastoma, while rs9884978 G>A and rs4834698 $\mathrm{T}>\mathrm{C}$ were associated with increased susceptibility to neuroblastoma [108].

\section{Glioblastoma}

Glioblastoma, which is the most common primary brain tumor, involves self-renewing glioblastoma stem cells (GSCs). The high mortality rate of glioblastoma is largely due to the tumor heterogeneity and therapeutic resistance of GSCs $[109,110]$. Studies have shown that METTL14 gene knockout significantly promotes the generation and development of GSCs, possibly by affecting the enrichment of ADAM19 $\mathrm{m}^{6} \mathrm{~A}$ to promote the expression of ADAM19, resulting in the self-renewal and tumorigenesis of GSCs [111].

\section{Kidney cancer}

Kidney cancer, also known as renal cell carcinoma (RCC), is a malignant tumor with the highest mortality rate in the genitourinary system, among which the most common pathological type is clear cell carcinoma of the kidney (ccRCC) [112]. According to statistics, the United States reports 73,820 cases a year and an estimated 14,770 deaths [113]. Compared with normal kidney tissue, the METTL14 mRNA level was significantly reduced in ccRCC [114]. Gong et al. confirmed that knockdown of METTL14 reduced $\mathrm{m}^{6} \mathrm{~A}$ levels and increased mRNA and protein levels of P2RX6, which then promoted the migration and invasion of RCC through the ATP-P2RX6$\mathrm{Ca}^{2+}$-P-ERK1/2-MMP9 signaling pathway [115]. Liu et al. found that METTL14 inhibited the proliferation and migration of renal carcinoma by inhibiting the expression 
of long noncoding RNA nuclear enriched abundant transcript 1_1 (NEAT1_1) by YTHDF2 [116]. METTL14 may be an independent prognostic indicator of RCC and ccRCC in univariate and multivariate Cox regression analyses [117-120]. The reduced METTL14 expression predicts a poor prognosis of the tumor. Studies have suggested that in RCC, the miRNA/mRNA-hsa-miR-13073p/METTL14 pathway may regulate the occurrence and development of tumors and play an important role in clinical applications [121]. In addition, some studies have found that METTL14 is positively correlated with PTEN [114], which indicates that METTL14 plays an inhibitory role in RCC by regulating PTEN. Notably, Zhang et al. revealed that knockdown down of METTL14 enhances the stability of bromodomain PHD finger transcription factor (BPTF) mRNA and activates downstream targets such as enolase 2 and SRC proto-oncogene nonreceptor tyrosine kinases, leading to glycolytic reprogramming that drives RCC metastasis [122]. This provides a mechanism for the synergistic effect of $\mathrm{m}^{6} \mathrm{~A}$ modification and glycolysis.

\section{Papillary thyroid carcinoma}

The most common type of thyroid cancer is papillary thyroid carcinoma (PTC), with an incidence of more than $80 \%$ and a 5 -year survival rate of more than $97 \%$ with a good prognosis [123]. Zhang et al. demonstrated through RIP and RNA pull-down analysis that lncRNA OIP5-AS1 is a gene downstream of METTL14, and that the overexpression of METTL14 regulates MEK/ERK and EGFR pathways through OIP5-AS1/miR-98/ADAMTS8, thus promoting the malignant behavior of PTC cells [124].

\section{Leukemia}

Acute myeloid leukemia (AML) is a common and deadly tumor of the blood system [125]. Alterations in $\mathrm{m}^{6} \mathrm{~A}$ levels can affect cell fate and differentiation status [126]. Sun et al. found that METTL14 levels were decreased in E/R positive patients compared with the control group, and it was speculated that the downregulation affected $\mathrm{m}^{6} \mathrm{~A}$ modification in related cancer cells, thereby promoting the occurrence of AML [127]. A five-center casecontrol study found that METTL14 gene rs $298982 \mathrm{G} / \mathrm{A}$ and rs1064034 T/A were significantly associated with a reduced risk of ALL in children [128]. METTL14 may be a potential biomarker for the prognosis of ALL.

\section{Other cancers}

In addition to the abovementioned tumors, METTL14 also acts as a tumor suppressor in other tumors. In lung adenocarcinoma (LUAD), Wang et al. found that METTL14 enhanced the stability of human leukocyte antigen complex group11 (HCG11) mRNA and inhibited the growth of lung adenocarcinoma via IGF2BP2/LATS1 [129]. The characteristic expression of the $\mathrm{m}^{6} \mathrm{~A}$ regulatory factor in castration-resistant prostate cancer (CRPC) and prostate cancer (PCa) was analyzed. METTL14 was downregulated and correlated with lymph node metastasis of CRPC and was negatively correlated with the Gleason grade in PCa [130]. METTL14 was downregulated in triple-negative breast cancer (TNBC) [118], esophageal cancer (EC) [131], gastric cancer [132], osteosarcoma (OS) [133],Wilms tumor, [134] and oral squamous cell carcinoma (OSCC) [135], and low METTL14 expression was related to poor prognosis. Notably, it has been confirmed that METTL14 knockout can activate Wnt and PI3K-Akt signals to promote the growth and invasion of gastric cancer cells [132]. Of course, these findings of MTTL14 need to be confirmed by subsequent studies.

\section{METTL14 acts as an oncogene}

Although many studies have shown an inhibitory effect on cancer, METTL14 has also been shown to stimulate the development and progression of tumors in some cases (Table 2). Wang et al. reported that $\mathrm{m}^{6} \mathrm{~A}$ levels were elevated in most pancreatic cancer samples and that METTL14 expression was significantly associated with survival. METTL14 overexpression reduces PERP mRNA and protein levels and promotes tumor cell migration and colony formation [136]. The CLK1-SRSF5 axis promotes the proliferation, migration, invasion, and colony formation of pancreatic cancer cells by inhibiting METTL14 ${ }^{\triangle \text { Exon10+ }}$ exon skipping and increasing the $\mathrm{m}^{6} \mathrm{~A}$ level [137]. METTL14 overexpression regulates the expression of hsa-miR$146 \mathrm{a}-5 \mathrm{p}$ through $\mathrm{m}^{6} \mathrm{~A}$ modification, thereby promoting breast cancer invasion and migration [138]. Sun et al. found that LINC00942, as an oncogene in the occurrence and development of BRCA tumors, promotes METTL14-mediated $\mathrm{m}^{6} \mathrm{~A}$ modification and regulates the mRNA stability and protein expression of the downstream genes CXCR4 and CYP1B1, thus promoting tumor growth and development. A new LINC00942-METTL14-CXCR4/CYP1B1 pathway was verified, providing a new approach for the diagnosis and treatment of BRCA [139]. Subsequently, Peng et al. found that the oncogene AURKA enhances the stability of DROSHA mRNA and promotes the oncogenic properties of the DROSHA-STC1 axis by inhibiting the ubiquitination-mediated degradation of the METTL14 protein and improving the recognition ability of IGF2BP2, leading to the malignant progression of breast cancer [140]. Therefore, it is reasonable to speculate that the upregulation of $\mathrm{m}^{6} \mathrm{~A}$ in peripheral blood may be a new biomarker for breast cancer and that the upregulation of METTL14 has a better diagnostic role 
Table 2 The function of METTL14 as an $\mathrm{m}^{6} \mathrm{~A}$ methyltransferase in human cancer

\begin{tabular}{|c|c|c|c|c|c|}
\hline Role & Cancer type & Upstream & Targets & Reader & Cellular function \\
\hline \multirow[t]{13}{*}{ Tumor suppressor } & $\begin{array}{l}\text { Colorectal cancer } \\
\text { Colorectal cancer }\end{array}$ & $\mathrm{MeCP} 2$ & $\begin{array}{l}\text { miR-375/YAP1 } \\
\text { miR-375/SP1 } \\
\text { KLF4 }\end{array}$ & IGF2BP2 & $\begin{array}{l}\text { Growth, migration, and invasion [81] } \\
\text { Proliferation, invasion, and metastasis [82] }\end{array}$ \\
\hline & Colorectal cancer & & SOX4 & YTHDF2 & Invasion and metastasis [83] \\
\hline & Colorectal cancer & & XIST & YTHDF2 & Proliferation and metastasis [84] \\
\hline & Liver cancer & & EGFR & & Migration, invasion, and EMT [91] \\
\hline & $\begin{array}{l}\text { Liver cancer } \\
\text { Liver cancer }\end{array}$ & & $\begin{array}{l}\text { miR-126 } \\
\text { USP48 }\end{array}$ & & $\begin{array}{l}\text { Invasion and metastasis [92] } \\
\text { Tumorigenesis [93] }\end{array}$ \\
\hline & Breast cancer & & & & Growth and metastasis [96] \\
\hline & Endometrial cancer & & $\begin{array}{l}\text { PHLPP2/ } \\
\text { mTORC2 }\end{array}$ & & Proliferation and tumorigenicity [102] \\
\hline & Bladder cancer & & Notch1 & & $\begin{array}{l}\text { Proliferation, self-renewal metastasis, and } \\
\text { tumorigenicity [104] }\end{array}$ \\
\hline & Bladder cancer & $\mathrm{FOXO3a}$ & Vimentin & & Migration, invasion, and EMT [105] \\
\hline & Glioblastoma & & ADAM19 & & Growth, self-renewal, and tumorigenesis [111] \\
\hline & $\begin{array}{l}\text { RCC } \\
\text { RCC } \\
\text { RCC }\end{array}$ & & $\begin{array}{l}\text { P2RX6 } \\
\text { NEAT1_1 } \\
\text { BPTF }\end{array}$ & & $\begin{array}{l}\text { Migration and invasion [115] } \\
\text { Growth and metastasis [116] } \\
\text { Metastasis and EMT [122] }\end{array}$ \\
\hline & $\begin{array}{l}\text { PTC } \\
\text { LUAD }\end{array}$ & & $\begin{array}{l}\text { OIP5-AS1 } \\
\text { HCG11 }\end{array}$ & IGF2BP2 & $\begin{array}{l}\text { Proliferation, migration, and invasion [124] } \\
\text { Growth [129] }\end{array}$ \\
\hline & Gastric cancer & & Wnt/PI3K-AKT & & Proliferation and invasion [132] \\
\hline \multirow[t]{5}{*}{ Oncogene } & Skin tumor & & DDB2 & & Autophagy [159] \\
\hline & Pancreatic cancer & & PERP & & Proliferation and migration [136] \\
\hline & Pancreatic cancer & CLK-1-SRSF5 & & & Invasion and metastasis [137] \\
\hline & Breast cancer & & hsa-miR-146a-5p & & Migration and invasion [138] \\
\hline & $\begin{array}{l}\text { Breast cancer } \\
\text { Breast cancer } \\
\text { AML }\end{array}$ & $\begin{array}{l}\text { LNC942 } \\
\text { AURKA } \\
\text { SPI1 }\end{array}$ & $\begin{array}{l}\text { CXCR4/ } \\
\text { CYP1B1 } \\
\text { DROSHA } \\
\text { MYB/MYC }\end{array}$ & IGF2BP2 & $\begin{array}{l}\text { Proliferation and growth [139] } \\
\text { Proliferation [140] } \\
\text { Survival and growth [18] }\end{array}$ \\
\hline
\end{tabular}

AML Acute myeloid leukemia, PTC Papillary thyroid carcinoma, LUAD Lung adenocarcinoma, RCC Renal cell carcinoma

in peripheral blood BC screening [141]. Similarly, Zhao et al. investigated whether $\mathrm{m}^{6} \mathrm{~A}$ RNA methylationrelated proteins can effectively predict the prognosis of head and neck squamous cell carcinoma (HNSCC). The results showed that the upregulation of METTL14 and WTAP may have a certain guiding significance for prognosis prediction [142]. In addition, Weng et al. reported that METTL14 blocked bone marrow differentiation and promoted cell proliferation in normal hematopoietic stem/progenitor cells (HSPCs) and AML. This occurred because METTL14-mediated $\mathrm{m}^{6} \mathrm{~A}$ modification improves the mRNA stability and translation of the downstream target gene $\mathrm{MYC} /$ MYB, whereas METTL14 is negatively regulated by SP1. In other words, when SPI1 expression is inhibited, METTL14 upregulates MYC/MYB expression, leading to blocked bone marrow differentiation and cancer [18]. In addition, Martin et al. demonstrated that lowering METTL14 and METTL3 levels promoted bone marrow differentiation [143]. The carcinogenic role of METTL14 in leukemia was emphasized (Fig. 4).

\section{Interaction of METTL14 with histone modifications}

In a study of embryonic neural stem cells (NSCs), Wang et al. found that knockdown of METTL14 significantly increased the level of acetylation of histone $\mathrm{H} 3$ at lysine 27 (H3K27ac), trimethylation of histone $\mathrm{H} 3$ at lysine 4 (H3K4me3), and trimethylation of histone $\mathrm{H} 3$ at lysine 27 (H3K27me3) and reduced the proliferation ability of neural stem cells. It was further verified that METTL14 regulates histone modification by enhancing the stability of H3K27ac CBP/p300 mRNA [144]. The interaction between $\mathrm{m}^{6} \mathrm{~A}$ and histone modification was revealed for the first time. Chen et al. reported that lysine-specific histone demethylation 5C (KDM5C) mediates the demethylation of H3K4me3 in the METTL14 promoter in colorectal cancer and inhibits the transcription of METTL14 [82]. On this basis, Wang et al. found that arginine methylation in the C-terminal region of METTL14 promoted the binding of METTL14 to RNA substrates, METTL3-14 methyltransferase activity and METTL14 interaction with RNA polymerase II [145]. Huang et al. demonstrated that H3K36me3 can directly 


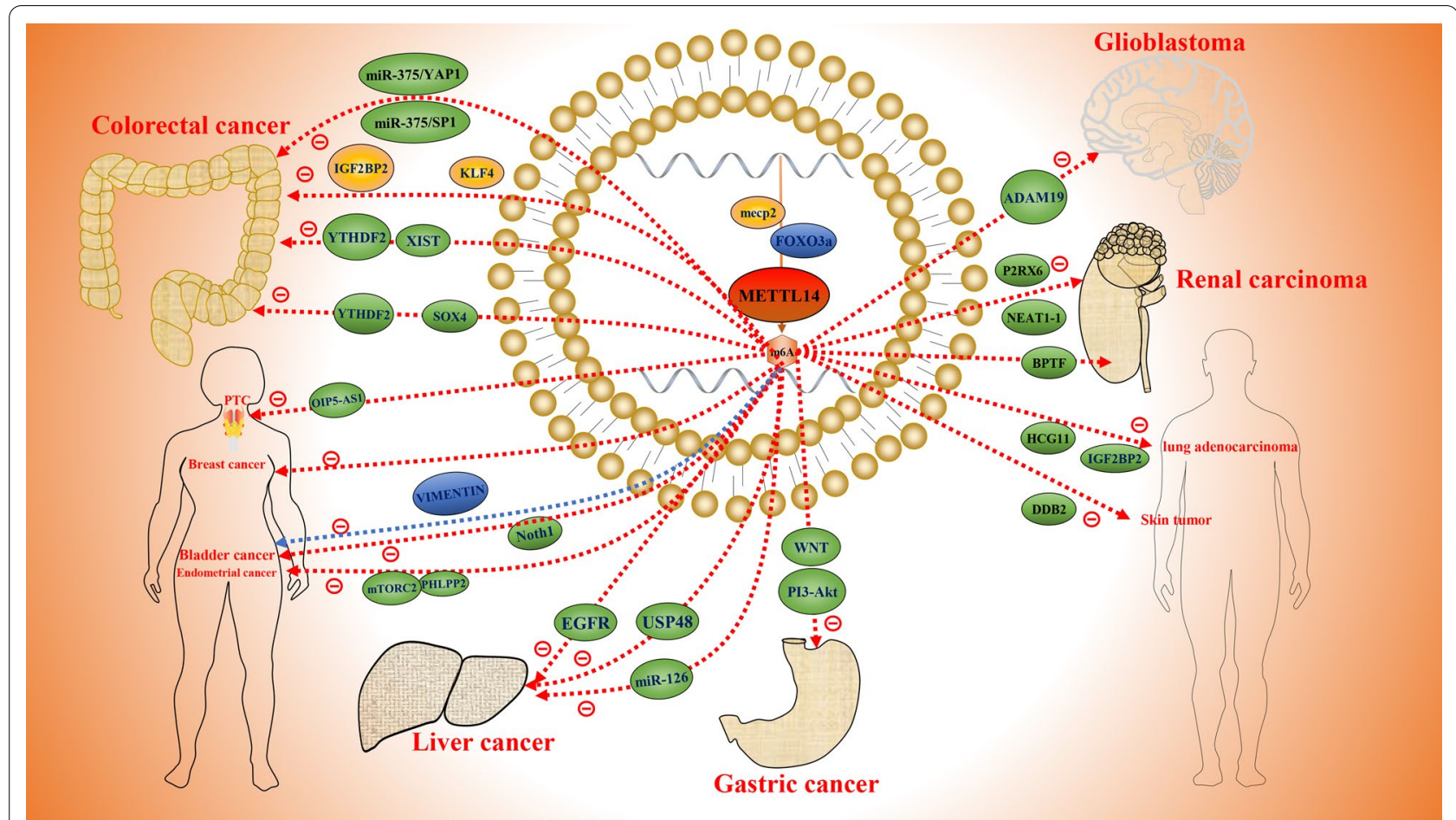

Fig. 4 The suppressive role of METTL14 in human cancers, including colorectal cancer, liver cancer, endometrial cancer, bladder cancer, glioblastoma, renal carcinoma, PTC, gastric cancer, breast cancer, skin tumor, and lung adenocarcinoma

bind to MTC, and that METTL14 recognizes the core region of H3K36me3 and collaborates with RNA polymerase II to induce methylation of new RNA [146, 147]. In conclusion, the above findings reveal the cross-talk between histone modification and $\mathrm{m}^{6} \mathrm{~A}$ modification at the level of epigenetic modification, revealing a new gene regulation mechanism and a further understanding of the recognition mechanism of METTL14.

\section{Potential clinical treatments}

By exploring the relationship between the immune system and tumorigenesis, immunotherapy has become an unprecedented treatment for many cancers [148]. Increased RNA methylation in anticancer immunotherapy affects immune responses [149]. Wang et al. found that inhibition of $\mathrm{m}^{6} \mathrm{~A}$ mRNA modification by deletion of METTL14 and METTL3 enhanced the response to programmed cell death-1 (PD-1) therapy in colorectal cancer. The proliferation of $\mathrm{CD}^{+} \mathrm{T}$ cells and the production of interferon (IFN)-C, CXCL9, and CXCL10 were also induced. It also promotes the accumulation of $\mathrm{CD}^{+}$and $\mathrm{CD}^{+}$effector $\mathrm{T}$ cells, which inhibit tumor growth, and enhance the efficacy of immunotherapy $[150,151]$. In the treatment of AML, all-trans retinoic acid/arsenic trioxide (ATO) [152], differentiation inducers (OP9 medium) [153], PMA [154], and all-trans retinoic acid (ATRA) [155] have been reported to significantly reduce $\mathrm{m}^{6} \mathrm{~A}$ levels and the expression of METTL14, thereby promoting myeloid differentiation and inhibiting leukemia growth [156]. In pancreatic cancer, knockout of METTL14 enhances the sensitivity of cancer cells to cisplatin by inducing apoptosis and autophagy through the mTOR signaling pathway [157] and inhibits the expression of cytidine deaminase (CDA), improving the sensitivity of drug-resistant cells to gemcitabine [158]. These studies demonstrate the importance of METTL14 inhibitors in the treatment of tumors. In addition, a recent study found that METTL14 regulates DDB2 translation to promote global genomic repair (GGR) and inhibits ultraviolet B (UVB) radiation to reduce the incidence of skin tumors [159]. Therefore, screening for and designing more effective METTL14 protein inhibitors and activators are expected to provide new anticancer drugs, and targeted therapies in combination with other drugs may become a panacea for controlling many diseases and other forms of cancer (Fig. 5).

\section{Conclusions and prospects}

The occurrence and development of cancer are mainly caused by abnormal genetic changes and epigenetic abnormalities. Abnormal inheritance includes gene mutation, deletion, amplification, and chromosomal 


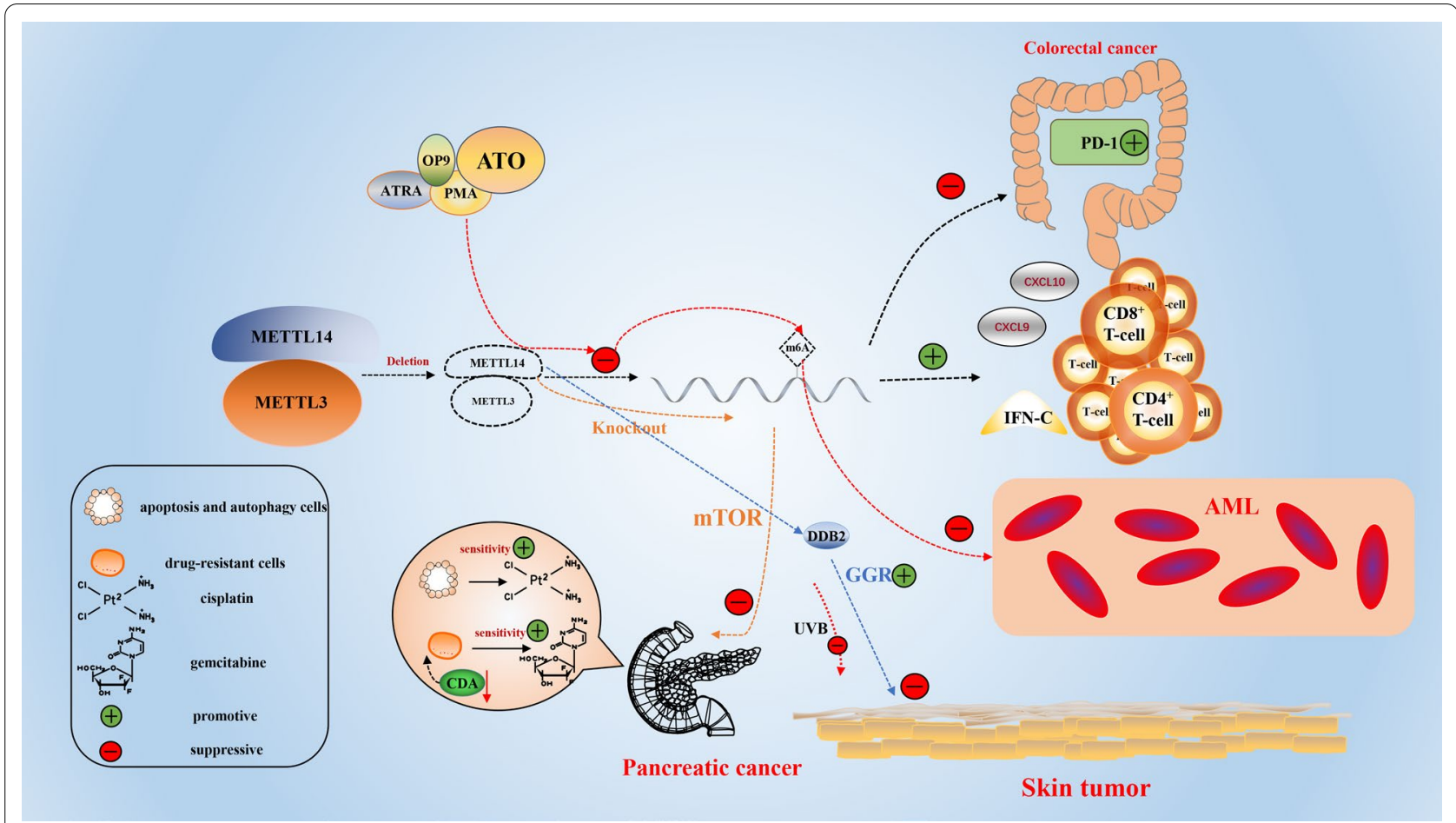

Fig. 5 The potential clinical role of METTL14 and METTL3 in certain cancers, including pancreatic cancer, skin tumor, colorectal cancer, and AML

translocation [40]. Epigenetics includes DNA, RNA, and histone modifications [160-163]. $\mathrm{m}^{6} \mathrm{~A}$ methylation is the most common internal modification of RNA and is of great significance for gene expression regulation [164, 165]. Changes in $\mathrm{m}^{6} \mathrm{~A}$-related genes or proteins affect a variety of biological processes that involve $\mathrm{m}^{6} \mathrm{~A}$ methylation, including viral infection [166], stress [167], heat shock [15], DNA damage [168], and the occurrence and development of cancer. It is worth noting that METTL14 can function independently of $\mathrm{m}^{6} \mathrm{~A}$. For example, Liu et al. found that the METTL3-METTL14 complex promotes transcription of the SASP gene and enhances immune surveillance, independent of changes in $\mathrm{m}^{6} \mathrm{~A}$ levels [169]. This article reminds us that hotspot proteins should be studied from multiple perspectives with innovative perspectives.

In recent years, with an increasing number of studies on METTL14, some breakthroughs have been made in some aspects, such as mechanisms and pathways of cancer and related metabolic processes, but at the same time, many problems have been exposed. First, METTL14 can recognize the structural support and recognition function of METTL3, but the specific structural basis and molecular mechanism of this recognition and support remain unclear. It is also unclear how METTL14 interacts with other MTC components during tumor development. Second, the METTL3-14 complex has been thought to play a synergistic role. However, studies have shown that METTL3 and METTL14 have opposite regulatory effects on HCC [170]. We hypothesized that METTL3 and METTL14 may have different target preferences and thus trigger different pathway effects. Of course, this requires further experimental verification. In addition, the $\mathrm{m}^{6} \mathrm{~A}$ locus of the METTL14 target gene has not been mapped in detail in specific studies of the METTL14 pathway. Finally, it is particularly emphasized that METTL14 has a dual regulatory effect on tumors, and attention should be paid to the use of METTL14 activators or inhibitors to avoid the occurrence of other tumors.

In summary, METTL14 plays an important role in a variety of tumors, regardless of whether they are dependent on $\mathrm{m}^{6} \mathrm{~A}$ modification. We look forward to further studies to optimize a targeted METTL14 treatment and enable its use widely in clinical practice.

\footnotetext{
Abbreviations

METTL14: Methyltransferase-like14; UTR: Untranslated region; MTC: Methyltransferase complex; hm6A: N6-hydroxymethyladenosine; f6A: N6-formyladenosine; ALKBH3: AlkB Homolog 3; IGF2BP: IGF2 mRNA binding protein; elF3: Eukaryotic initiation factor 3; WTAP: Wilms tumor 1 associated protein; RBM: RNA-binding motif protein; ZC3H13: Zinc finger CCCH-type containing 13; VIRMA: Vir-like $\mathrm{m}^{6} \mathrm{~A}$ methyltransferase-associated; CBLL1: Cbl proto-oncogene like1; MAC: M ${ }^{6}$ A-METTL Complex; MACOM: M ${ }^{6}$ A-METTL associated complexes; MTD: Methylation transferase domain; SAM: S-adenosylmethionine; CRC: Colorectal cancer; YAP: Yes-associated protein 1; SOX4: SRY-related
} 
high-mobility-group box 4; EMT: Epithelial-mesenchymal transformation; KLF4: Kruppel like factor 4; TAM: Tumor-associated macrophage; HCC: Hepatocellular carcinoma; CSAD: Cysteine sulfonate decarboxylase; GOT2: Glutamic oxalacetic transaminase 2; SOCS2: Cytokine signaling inhibitor 2; AML: Acute myeloid leukemia; EC: Endometrial cancer; BC: Bladder cancer; TICs: Tumorinitiating cells; ISO: Isorhapontigenin; GSCs: Glioblastoma stem cells; RCC : Renal cell carcinoma; PTC: Papillary thyroid carcinoma; PCa: Prostate cancer; NEAT: Nuclear enriched abundant transcript; BPTF: Bromodomain PHD finger transcription factor; LUAD: Lung adenocarcinoma; HCG11: Human leukocyte antigen complex group 11; OSCC: Oral squamous cell carcinoma; CRPC: Castration-resistant prostate cancer; TNBC: Triple-negative breast cancer; EC: Esophageal cancer; OS: Osteosarcoma; MeCP2: Methyl CpG-binding protein 2; HNSCC: Head and neck squamous cell carcinoma; KDM5C: Lysine-specific histone demethylation 5C; H3K4me3: H3 lysine 4 trimethylation; PD-1: Programmed cell death-1; ATRA: All-trans retinoic acid; CDA: Cytidine deaminase; UVB: Ultraviolet B.

\section{Acknowledgements}

We apologize to the colleagues whose work could not be cited due to space constraints.

\section{Authors' contributions}

QG, HRL and LM collected the related literature. QG, HRL, LM, HQG and YPC wrote the manuscript. ZJZ and JH participated in the design of the review and revised the manuscript. All authors have read and approved the final manuscript.

\section{Funding}

This study was supported by grants from the National Natural Science Foundation of China (82173593, 82002636, 82002635), China Postdoctoral Science Foundation (2020T130132, 2020M682668), and Guangzhou Science and Technology Project (202102020421).

Availability of data and materials

Not applicable.

\section{Declarations}

\section{Ethics approval and consent to participate}

Not applicable.

\section{Consent for publication}

Not applicable.

\section{Competing interests}

The authors declare that they have no competing interests.

\section{Author details}

1 Department of Pediatric Surgery, Guangzhou Institute of Pediatrics, Guangdong Provincial Key Laboratory of Research in Structural Birth Defect Disease, Guangzhou Women and Children's Medical Center, Guangzhou Medical University, 9 Jinsui Road, Guangzhou 510623, Guangdong, China. ${ }^{2}$ School of Medicine, South China University of Technology, Guangzhou 510006, Guangdong, China. ${ }^{3}$ Faculty of Medicine, Macau University of Science and Technology, Macau 999078, China. ${ }^{4}$ Laboratory Animal Center, School of Chemical Biology and Biotechnology, Peking University Shenzhen Graduate School, Shenzhen 518055, China.

Received: 29 October 2021 Accepted: 24 January 2022 Published online: 03 February 2022

\section{References}

1. Wei CM, Gershowitz A, Moss B. Methylated nucleotides block 5'terminus of HeLa cell messenger RNA. Cell. 1975;4:379-86.

2. Tang Y, Chen K, Song B, Ma J, Wu X, Xu Q, Wei Z, Su J, Liu G, Rong R, et al. m6A-Atlas: a comprehensive knowledgebase for unraveling the N6-methyladenosine (m6A) epitranscriptome. Nucleic Acids Res. 2021;49:D134-d143.
3. Liu T, Wei Q, Jin J, Luo Q, Liu Y, Yang Y, Cheng C, Li L, Pi J, Si Y, et al. The m6A reader YTHDF1 promotes ovarian cancer progression via augmenting EIF3C translation. Nucleic Acids Res. 2020;48:3816-31.

4. Deng X, Chen K, Luo GZ, Weng X, Ji Q, Zhou T, He C. Widespread occurrence of N6-methyladenosine in bacterial mRNA. Nucleic Acids Res. 2015;43:6557-67.

5. Bokar JA, Shambaugh ME, Polayes D, Matera AG, Rottman FM. Purification and cDNA cloning of the AdoMet-binding subunit of the human mRNA (N6-adenosine)-methyltransferase. RNA. 1997:3:1233-47.

6. Zhao BS, Roundtree IA, He C. Post-transcriptional gene regulation by mRNA modifications. Nat Rev Mol Cell Biol. 2017;18:31-42.

7. Roundtree IA, Evans ME, Pan T, He C. Dynamic RNA modifications in gene expression regulation. Cell. 2017;169:1187-200.

8. Du Y, Hou G, Zhang H, Dou J, He J, Guo Y, Li L, Chen R, Wang Y, Deng R, et al. SUMOylation of the m6A-RNA methyltransferase METTL3 modulates its function. Nucleic Acids Res. 2018;46:5195-208.

9. Matsui M, Corey DR. Non-coding RNAs as drug targets. Nat Rev Drug Discov. 2017;16:167-79.

10. Zhu KP, Zhang CL, Ma XL, Hu JP, Cai T, Zhang L. Analyzing the interactions of mRNAs and ncRNAs to predict competing endogenous RNA networks in osteosarcoma chemo-resistance. Mol Ther. 2019;27:518-30.

11. Alarcón CR, Lee H, Goodarzi H, Halberg N, Tavazoie SF. N6-methyladenosine marks primary microRNAs for processing. Nature. 2015;519:482-5.

12. Meyer KD, Patil DP, Zhou J, Zinoviev A, Skabkin MA, Elemento O, Pestova TV, Qian SB, Jaffrey SR. 5' UTR m(6)A promotes cap-independent translation. Cell. 2015;163:999-1010.

13. Guo X, Li K, Jiang W, Hu Y, Xiao W, Huang Y, Feng Y, Pan Q, Wan R. RNA demethylase ALKBH5 prevents pancreatic cancer progression by posttranscriptional activation of PER1 in an m6A-YTHDF2-dependent manner. Mol Cancer. 2020;19:91.

14. Lin Z, Hsu PJ, Xing X, Fang J, Lu Z, Zou Q, Zhang KJ, Zhang X, Zhou Y, Zhang T, et al. Mettl3-/Mettl14-mediated mRNA N(6)-methyladenosine modulates murine spermatogenesis. Cell Res. 2017;27:1216-30.

15. Zhou J, Wan J, Gao X, Zhang X, Jaffrey SR, Qian SB. Dynamic m(6)A mRNA methylation directs translational control of heat shock response. Nature. 2015;526:591-4

16. Geula S, Moshitch-Moshkovitz S, Dominissini D, Mansour AA, Kol N, Salmon-Divon M, Hershkovitz V, Peer E, Mor N, Manor YS, et al. Stem cells. m6A mRNA methylation facilitates resolution of naïve pluripotency toward differentiation. Science. 2015;347:1002-6.

17. Liu ZX, Li LM, Sun HL, Liu SM. Link between m6A modification and cancers. Front Bioeng Biotechnol. 2018;6:89.

18. Weng $H$, Huang $H$, Wu H, Qin X, Zhao BS, Dong L, Shi H, Skibbe J, Shen C, Hu C, et al. METTL14 inhibits hematopoietic stem/progenitor differentiation and promotes leukemogenesis via mRNA m(6)A modification. Cell Stem Cell. 2018;22:191-205.e199.

19. Chang G, Shi L, Ye Y, Shi H, Zeng L, Tiwary S, Huse JT, Huo L, Ma L, Ma Y, et al. YTHDF3 induces the translation of m(6)A-enriched gene transcripts to promote breast cancer brain metastasis. Cancer Cell. 2020;38:857-871.e857.

20. Li HB, Tong J, Zhu S, Batista PJ, Duffy EE, Zhao J, Bailis W, Cao G, Kroehling L, Chen Y, et al. m(6)A mRNA methylation controls T cell homeostasis by targeting the IL-7/STAT5/SOCS pathways. Nature. 2017; 548:338-42.

21. Frye M, Harada BT, Behm M, He C. RNA modifications modulate gene expression during development. Science. 2018;361:1346-9.

22. Han J, Wang JZ, Yang X, Yu H, Zhou R, Lu HC, Yuan WB, Lu JC, Zhou ZJ, Lu Q, et al. METTL3 promote tumor proliferation of bladder cancer by accelerating pri-miR221/222 maturation in m6A-dependent manner. Mol Cancer. 2019;18:110.

23. Li L, Zang L, Zhang F, Chen J, Shen H, Shu L, Liang F, Feng C, Chen D, Tao $\mathrm{H}$, et al. Fat mass and obesity-associated (FTO) protein regulates adult neurogenesis. Hum Mol Genet. 2017;26:2398-411.

24. Tuck MT. Partial purification of a 6-methyladenine mRNA methyltransferase which modifies internal adenine residues. Biochem J. 1992;288(Pt 1):233-40.

25. Dominissini D, Moshitch-Moshkovitz S, Schwartz S, Salmon-Divon M, Ungar L, Osenberg S, Cesarkas K, Jacob-Hirsch J, Amariglio N, Kupiec $M$, et al. Topology of the human and mouse m6A RNA methylomes revealed by m6A-seq. Nature. 2012;485:201-6. 
26. Li N, Kang Y, Wang L, Huff S, Tang R, Hui H, Agrawal K, Gonzalez GM, Wang Y, Patel SP, Rana TM. ALKBH5 regulates anti-PD-1 therapy response by modulating lactate and suppressive immune cell accumulation in tumor microenvironment. Proc Natl Acad Sci USA. 2020;117:20159-70.

27. Liu N, Pan T. N6-methyladenosine-encoded epitranscriptomics. Nat Struct Mol Biol. 2016;23:98-102.

28. Jia G, Fu Y, Zhao X, Dai Q, Zheng G, Yang Y, Yi C, Lindahl T, Pan T, Yang YG, He C. N6-methyladenosine in nuclear RNA is a major substrate of the obesity-associated FTO. Nat Chem Biol. 2011;7:885-7.

29. Zhao X, Yang Y, Sun BF, Shi Y, Yang X, Xiao W, Hao YJ, Ping XL, Chen YS, Wang WJ, et al. FTO-dependent demethylation of N6-methyladenosine regulates mRNA splicing and is required for adipogenesis. Cell Res. 2014;24:1403-19.

30. Wu R, Liu Y, Yao Y, Zhao Y, Bi Z, Jiang Q, Liu Q, Cai M, Wang F, Wang Y, Wang $X$. FTO regulates adipogenesis by controlling cell cycle progression via m(6)A-YTHDF2 dependent mechanism. Biochim Biophys Acta Mol Cell Biol Lipids. 2018;1863:1323-30.

31. Zheng G, Dahl JA, Niu Y, Fedorcsak P, Huang CM, Li CJ, Vågbø CB, Shi $Y$, Wang WL, Song $\mathrm{SH}$, et al. ALKBH5 is a mammalian RNA demethylase that impacts RNA metabolism and mouse fertility. Mol Cell. 2013:49:18-29.

32. Wang T, Kong S, Tao M, Ju S. The potential role of RNA N6-methyladenosine in cancer progression. Mol Cancer. 2020;19:88.

33. Ueda Y, Ooshio I, Fusamae Y, Kitae K, Kawaguchi M, Jingushi K, Hase H, Harada K, Hirata K, Tsujikawa K. AlkB homolog 3-mediated tRNA demethylation promotes protein synthesis in cancer cells. Sci Rep. 2017;7:42271.

34. Chen Z, Qi M, Shen B, Luo G, Wu Y, Li J, Lu Z, Zheng Z, Dai Q, Wang $H$. Transfer RNA demethylase ALKBH3 promotes cancer progression via induction of tRNA-derived small RNAs. Nucleic Acids Res. 2019:47:2533-45.

35. Wang X, Zhao BS, Roundtree IA, Lu Z, Han D, Ma H, Weng X, Chen K, Shi $\mathrm{H}, \mathrm{He}$ C. N(6)-methyladenosine modulates messenger RNA translation efficiency. Cell. 2015;161:1388-99.

36. Wang X, Lu Z, Gomez A, Hon GC, Yue Y, Han D, Fu Y, Parisien M, Dai Q, Jia $\mathrm{G}$, et al. N6-methyladenosine-dependent regulation of messenger RNA stability. Nature. 2014;505:117-20.

37. Xiao W, Adhikari S, Dahal U, Chen YS, Hao YJ, Sun BF, Sun HY, Li A, Ping $\mathrm{XL}$, Lai WY, et al. Nuclear $\mathrm{m}(6) \mathrm{A}$ reader $\mathrm{YTHDC} 1$ regulates $\mathrm{mRNA}$ splicing. Mol Cell. 2016;61:507-19.

38. Hsu PJ, Zhu Y, Ma H, Guo Y, Shi X, Liu Y, Qi M, Lu Z, Shi H, Wang J, et al. Ythdc2 is an N(6)-methyladenosine binding protein that regulates mammalian spermatogenesis. Cell Res. 2017;27:1115-27.

39. Shi H, Wang X, Lu Z, Zhao BS, Ma H, Hsu PJ, Liu C, He C. YTHDF3 facilitates translation and decay of N(6)-methyladenosine-modified RNA. Cell Res. 2017;27:315-28.

40. Deng X, Su R, Weng H, Huang H, Li Z, Chen J. RNA N(6)-methyladenosine modification in cancers: current status and perspectives. Cell Res. 2018;28:507-17.

41. Huang $H$, Weng $H$, Sun W, Qin X, Shi H, Wu H, Zhao BS, Mesquita A, Liu C, Yuan CL, et al. Recognition of RNA N(6)-methyladenosine by IGF2BP proteins enhances mRNA stability and translation. Nat Cell Biol. 2018;20:285-95.

42. Lin S, Choe J, Du P, Triboulet R, Gregory RI. The m(6)A methyltransferase METTL3 promotes translation in human cancer cells. Mol Cell. 2016;62:335-45

43. Dai D, Wang H, Zhu L, Jin H, Wang X. N6-methyladenosine links RNA metabolism to cancer progression. Cell Death Dis. 2018;9:124

44. Liu N, Zhou Kl, Parisien M, Dai Q, Diatchenko L, Pan T. N6-methyladenosine alters RNA structure to regulate binding of a low-complexity protein. Nucleic Acids Res. 2017;45:6051-63.

45. Alarcón CR, Goodarzi H, Lee H, Liu X, Tavazoie S, Tavazoie SF. HNRNPA2B1 Is a mediator of m(6)A-dependent nuclear RNA processing events. Cell. 2015;162:1299-308.

46. Li Y, Gu J, Xu F, Zhu Q, Chen Y, Ge D, Lu C. Molecular characterization, biological function, tumor microenvironment association and clinical significance of m6A regulators in lung adenocarcinoma. Brief Bioinform 2020

47. Jin H, Ying $X$, Que B, Wang $X$, Chao Y, Zhang H, Yuan Z, Qi D, Lin S, Min $W$, et al. N(6)-methyladenosine modification of ITGA6 mRNA promotes the development and progression of bladder cancer. EBioMedicine. 2019;47:195-207.

48. Chen M, Wei L, Law CT, Tsang FH, Shen J, Cheng CL, Tsang LH, Ho DW, Chiu DK, Lee JM, et al. RNA N6-methyladenosine methyltransferase-like 3 promotes liver cancer progression through YTHDF2-dependent posttranscriptional silencing of SOCS2. Hepatology. 2018;67:2254-70.

49. Ping XL, Sun BF, Wang L, Xiao W, Yang X, Wang WJ, Adhikari S, Shi Y, Lv $Y$, Chen YS, et al. Mammalian WTAP is a regulatory subunit of the RNA N6-methyladenosine methyltransferase. Cell Res. 2014;24:177-89.

50. lanniello Z, Paiardini A, Fatica A. N(6)-methyladenosine (m(6)A): a promising new molecular target in acute myeloid leukemia. Front Oncol. 2019;9:251.

51. Yue Y, Liu J, Cui X, Cao J, Luo G, Zhang Z, Cheng T, Gao M, Shu X, Ma H, et al. VIRMA mediates preferential m(6)A mRNA methylation in $3^{\prime} U T R$ and near stop codon and associates with alternative polyadenylation. Cell Discov. 2018:4:10.

52. Huang $\mathrm{H}$, Weng $\mathrm{H}$, Chen J. m(6)A modification in coding and noncoding RNAs: roles and therapeutic implications in cancer. Cancer Cell. 2020;37:270-88.

53. Patil DP, Chen CK, Pickering BF, Chow A, Jackson C, Guttman M, Jaffrey SR. m(6)A RNA methylation promotes XIST-mediated transcriptional repression. Nature. 2016;537:369-73.

54. Wu B, Li L, Huang Y, Ma J, Min J. Readers, writers and erasers of N(6)-methylated adenosine modification. Curr Opin Struct Biol. 2017:47:67-76.

55. Knuckles P, Lence T, Haussmann IU, Jacob D, Kreim N, Carl SH, Masiello I, Hares T, Villaseñor R, Hess D, et al. Zc3h13/Flacc is required for adenosine methylation by bridging the mRNA-binding factor Rbm15/ Spenito to the m(6)A machinery component Wtap/FI(2)d. Genes Dev. 2018:32:415-29

56. Pendleton KE, Chen B, Liu K, Hunter OV, Xie Y, Tu BP, Conrad NK. The U6 snRNA m(6)A methyltransferase METTL16 regulates SAM synthetase intron retention. Cell. 2017;169:824-835.e814.

57. Warda AS, Kretschmer J, Hackert P, Lenz C, Urlaub H, Höbartner C, Sloan $\mathrm{KE}$, Bohnsack MT. Human METTL16 is a N(6)-methyladenosine ( $\mathrm{m}(6)$ A) methyltransferase that targets pre-mRNAs and various non-coding RNAs. EMBO Rep. 2017;18:2004-14.

58. Ignatova W, Stolz P, Kaiser S, Gustafsson TH, Lastres PR, Sanz-Moreno A, Cho YL, Amarie OV, Aguilar-Pimentel A, Klein-Rodewald T, et al. The rRNA m(6)A methyltransferase METTL5 is involved in pluripotency and developmental programs. Genes Dev. 2020;34:715-29.

59. van Tran N, Ernst FGM, Hawley BR, Zorbas C, Ulryck N, Hackert P, Bohnsack KE, Bohnsack MT, Jaffrey SR, Graille M, Lafontaine DLJ. The human 18S rRNA m6A methyltransferase METTL5 is stabilized by TRMT112. Nucleic Acids Res. 2019;47:7719-33.

60. Pinto R, Vågbø CB, Jakobsson ME, Kim Y, Baltissen MP, O'Donohue MF, Guzmán UH, Małecki JM, Wu J, Kirpekar F, et al. The human methyltransferase ZCCHC4 catalyses N6-methyladenosine modification of $28 \mathrm{~S}$ ribosomal RNA. Nucleic Acids Res. 2020;48:830-46.

61. Ren W, Lu J, Huang M, Gao L, Li D, Wang GG, Song J. Structure and regulation of ZCCHC4 in m(6)A-methylation of $28 \mathrm{~S}$ rRNA. Nat Commun. 2019;10:5042

62. Ma H, Wang X, Cai J, Dai Q, Natchiar SK, Lv R, Chen K, Lu Z, Chen H, Shi YG, et al. N(6-)Methyladenosine methyltransferase ZCCHC4 mediates ribosomal RNA methylation. Nat Chem Biol. 2019;15:88-94.

63. An S, Huang W, Huang $X$, Cun Y, Cheng W, Sun X, Ren Z, Chen Y, Chen W, Wang J. Integrative network analysis identifies cell-specific trans regulators of m6A. Nucleic Acids Res. 2020;48:1715-29.

64. Zaccara S, Ries RJ, Jaffrey SR. Reading, writing and erasing mRNA methylation. Nat Rev Mol Cell Biol. 2019;20:608-24.

65. Meyer KD, Jaffrey SR. Rethinking m(6)A readers, writers, and erasers. Annu Rev Cell Dev Biol. 2017;33:319-42.

66. Zhou Kl, Pan T. Structures of the m(6)A methyltransferase complex: two subunits with distinct but coordinated roles. Mol Cell. 2016;63:183-5.

67. Tong J, Flavell RA, Li HB. RNA m(6)A modification and its function in diseases. Front Med. 2018;12:481-9.

68. Sun T, Wu R, Ming L. The role of m6A RNA methylation in cancer. Biomed Pharmacother. 2019;112:108613.

69. Liu J, Yue Y, Han D, Wang X, Fu Y, Zhang L, Jia G, Yu M, Lu Z, Deng X, et al. A METTL3-METTL14 complex mediates mammalian nuclear RNA N6-adenosine methylation. Nat Chem Biol. 2014;10:93-5. 
70. Wang P, Doxtader KA, Nam Y. Structural basis for cooperative function of Mettl3 and Mettl14 methyltransferases. Mol Cell. 2016;63:306-17.

71. Wang X, Feng J, Xue Y, Guan Z, Zhang D, Liu Z, Gong Z, Wang Q, Huang J, Tang C, et al. Structural basis of N(6)-adenosine methylation by the METTL3-METTL14 complex. Nature. 2016;534:575-8.

72. Huang J, Yin P. Structural insights into N(6)-methyladenosine ( $m(6)$ A) modification in the transcriptome. Genom Proteom Bioinf. 2018;16:85-98.

73. Śledź $P$, Jinek M. Structural insights into the molecular mechanism of the m(6)A writer complex. Elife 2016, 5 .

74. Schöller E, Weichmann F, Treiber T, Ringle S, Treiber N, Flatley A, Feederle R, Bruckmann A, Meister G. Interactions, localization, and phosphorylation of the m(6)A generating METTL3-METTL14-WTAP complex. RNA. 2018;24:499-512.

75. Zhang $X$, Blumenthal RM, Cheng $X$. A role for N6-methyladenine in DNA damage repair. Trends Biochem Sci. 2021;46:175-83.

76. Woodcock CB, Yu D, Hajian T, Li J, Huang Y, Dai N, Corrêa IR Jr, Wu T, Vedadi M, Zhang X, Cheng X. Human MettL3-MettL14 complex is a sequence-specific DNA adenine methyltransferase active on singlestrand and unpaired DNA in vitro. Cell Discov. 2019;5:63.

77. Wang J, Zhang Y, Song H, Yin H, Jiang T, Xu Y, Liu L, Wang H, Gao H, Wang $\mathrm{R}$, Song J. The circular RNA circSPARC enhances the migration and proliferation of colorectal cancer by regulating the JAK/STAT pathway. Mol Cancer. 2021;20:81.

78. Weitz J, Koch M, Debus J, Höhler T, Galle PR, Büchler MW. Colorectal cancer. Lancet. 2005;365:153-65.

79. Brody H. Colorectal cancer. Nature. 2015;521:S1.

80. Liu X, Liu L, Dong Z, Li J, Yu Y, Chen X, Ren F, Cui G, Sun R. Expression patterns and prognostic value of m(6)A-related genes in colorectal cancer. Am J Transl Res. 2019;11:3972-91.

81. Chen X, Xu M, Xu X, Zeng K, Liu X, Sun L, Pan B, He B, Pan Y, Sun H, et al. METTL14 suppresses CRC progression via regulating N6-methyladenosine-dependent primary miR-375 processing. Mol Ther. 2020;28:599-612

82. Wang S, Gan M, Chen C, Zhang Y, Kong J, Zhang H, Lai M. Methyl CpG binding protein 2 promotes colorectal cancer metastasis by regulating $\mathrm{N}(6)$-methyladenosine methylation through methyltransferase-like 14. Cancer Sci 2021

83. Chen X, Xu M, Xu X, Zeng K, Liu X, Pan B, Li C, Sun L, Qin J, Xu T, et al. METTL14-mediated N6-methyladenosine modification of SOX4 mRNA inhibits tumor metastasis in colorectal cancer. Mol Cancer. 2020;19:106.

84. Yang X, Zhang S, He C, Xue P, Zhang L, He Z, Zang L, Feng B, Sun J, Zheng M. METTL14 suppresses proliferation and metastasis of colorectal cancer by down-regulating oncogenic long non-coding RNA XIST. Mol Cancer. 2020;19:46.

85. Chen Y, Wang S, Cho WC, Zhou X, Zhang Z. Prognostic implication of the $m(6) A$ RNA methylation regulators in rectal cancer. Front Genet. 2021;12:604229.

86. Dong L, Chen C, Zhang Y, Guo P, Wang Z, Li J, Liu Y, Liu J, Chang R, Li $Y$, et al. The loss of RNA N(6)-adenosine methyltransferase Mettl14 in tumor-associated macrophages promotes CD8(+)T cell dysfunction and tumor growth. Cancer Cell 2021.

87. Zuo X, Chen Z, Gao W, Zhang Y, Wang J, Wang J, Cao M, Cai J, Wu J, Wang X. M6A-mediated upregulation of LINC00958 increases lipogenesis and acts as a nanotherapeutic target in hepatocellular carcinoma. J Hematol Oncol. 2020;13:5

88. Chen Y, Peng C, Chen J, Chen D, Yang B, He B, Hu W, Zhang Y, Liu H, Dai $L$, et al. WTAP facilitates progression of hepatocellular carcinoma via m6A-HuR-dependent epigenetic silencing of ETS1. Mol Cancer. 2019:18:127.

89. Yang JD, Hainaut P, Gores GJ, Amadou A, Plymoth A, Roberts LR. A global view of hepatocellular carcinoma: trends, risk, prevention and management. Nat Rev Gastroenterol Hepatol. 2019;16:589-604.

90. Chen M, Wong CM. The emerging roles of N6-methyladenosine (m6A) deregulation in liver carcinogenesis. Mol Cancer. 2020;19:44.

91. Shi Y, Zhuang Y, Zhang J, Chen M, Wu S. METTL14 inhibits hepatocellular carcinoma metastasis through regulating EGFR/PI3K/AKT signaling pathway in an m6A-dependent manner. Cancer Manag Res. 2020;12:13173-84.

92. Ma JZ, Yang F, Zhou CC, Liu F, Yuan JH, Wang F, Wang TT, Xu QG, Zhou WP, Sun SH. METTL14 suppresses the metastatic potential of hepatocellular carcinoma by modulating N(6) -methyladenosine-dependent primary MicroRNA processing. Hepatology. 2017:65:529-43.

93. Du L, Li Y, Kang M, Feng M, Ren Y, Dai H, Wang Y, Wang Y, Tang $B$. USP48 is upregulated by Mettl14 to attenuate hepatocellular carcinoma via regulating SIRT6 stabilization. Cancer Res 2021.

94. Li Z, Li F, Peng Y, Fang J, Zhou J. Identification of three m6A-related mRNAs signature and risk score for the prognostication of hepatocellular carcinoma. Cancer Med. 2020:9:1877-89.

95. Niu Y, Lin Z, Wan A, Chen H, Liang H, Sun L, Wang Y, Li X, Xiong XF, Wei B, et al. RNA N6-methyladenosine demethylase FTO promotes breast tumor progression through inhibiting BNIP3. Mol Cancer. 2019:18:46.

96. Wu L, Wu D, Ning J, Liu W, Zhang D. Changes of N6-methyladenosine modulators promote breast cancer progression. BMC Cancer. 2019:19:326.

97. Gong PJ, Shao YC, Yang Y, Song WJ, He X, Zeng YF, Huang SR, Wei L, Zhang JW. Analysis of N6-methyladenosine methyltransferase reveals METTL14 and ZC3H13 as tumor suppressor genes in breast cancer. Front Oncol. 2020;10:578963.

98. Dong XF, Wang Y, Huang BF, Hu GN, Shao JK, Wang Q, Tang CH, Wang CQ. Downregulated METTL14 expression correlates with breast cancer tumor grade and molecular classification. Biomed Res Int 2020;2020:8823270.

99. Zhang L, Wan Y, Zhang Z, Jiang Y, Gu Z, Ma X, Nie S, Yang J, Lang J, Cheng W, Zhu L. IGF2BP1 overexpression stabilizes PEG10 mRNA in an m6A-dependent manner and promotes endometrial cancer progression. Theranostics. 2021;11:1100-14.

100. Xue T, Liu X, Zhang M, Liu S, Zou M, Li Y, Ma Z, Han Y, Thompson P, Zhang X.PADI2-catalyzed MEK1 citrullination activates ERK1/2 and promotes IGF2BP1-mediated SOX2 mRNA stability in endometrial cancer. Adv Sci (Weinh). 2021;8:2002831.

101. Ma J, Yang D, Ma XX. Immune infiltration-related N6-methyladenosine RNA methylation regulators influence the malignancy and prognosis of endometrial cancer. Aging (Albany NY). 2021;13:16287-315.

102. Liu J, Eckert MA, Harada BT, Liu SM, Lu Z, Yu K, Tienda SM, Chryplewicz A, Zhu AC, Yang Y, et al. m(6)A mRNA methylation regulates AKT activity to promote the proliferation and tumorigenicity of endometrial cancer. Nat Cell Biol. 2018;20:1074-83.

103. Xie F, Huang C, Liu F, Zhang H, Xiao X, Sun J, Zhang X, Jiang G. CircPTPRA blocks the recognition of RNA N(6)-methyladenosine through interacting with IGF2BP1 to suppress bladder cancer progression. Mol Cancer. 2021;20:68.

104. Gu C, Wang Z, Zhou N, Li G, Kou Y, Luo Y, Wang Y, Yang J, Tian F. Mettl14 inhibits bladder TIC self-renewal and bladder tumorigenesis through N(6)-methyladenosine of Notch1. Mol Cancer. 2019;18:168.

105. Zhang N, Hua X, Tu H, Li J, Zhang Z, Max C. Isorhapontigenin (ISO) inhibits EMT through FOXO3A/METTL14/VIMENTIN pathway in bladder cancer cells. Cancer Lett. 2021:520:400-8.

106. Cheng J, Xu L, Deng L, Xue L, Meng Q, Wei F, Wang J. RNA N(6)-methyladenosine modification is required for miR-98/MYCN axis-mediated inhibition of neuroblastoma progression. Sci Rep. 2020;10:13624.

107. Wang $Z$, Cheng $H, X u H, Y u X$, Sui D. A five-gene signature derived from $m 6$ A regulators to improve prognosis prediction of neuroblastoma. Cancer Biomark. 2020;28:275-84.

108. Zhuo Z, Lu H, Zhu J, Hua RX, Li Y, Yang Z, Zhang J, Cheng J, Zhou $\mathrm{H}$, Li S, et al. METTL14 gene polymorphisms confer neuroblastoma susceptibility: an eight-center case-control study. Mol Ther Nucleic Acids. 2020;22:17-26.

109. Dixit D, Prager BC, Gimple RC, Poh HX, Wang Y, Wu Q, Qiu Z, Kidwell $\mathrm{RL}$, Kim LJY, Xie Q, et al. The RNA m6A reader YTHDF2 maintains oncogene expression and is a targetable dependency in glioblastoma stem cells. Cancer Discov. 2021;11:480-99.

110. Zhang S, Zhao BS, Zhou A, Lin K, Zheng S, Lu Z, Chen Y, Sulman EP, Xie K, Bögler O, et al. m(6)A demethylase ALKBH5 maintains tumorigenicity of glioblastoma stem-like cells by sustaining FOXM1 expression and cell proliferation program. Cancer Cell. 2017;31:591$606 . e 596$.

111. Cui Q, Shi H, Ye P, Li L, Qu Q, Sun G, Sun G, Lu Z, Huang Y, Yang CG, et al. m(6)A RNA methylation regulates the self-renewal and tumorigenesis of glioblastoma stem cells. Cell Rep. 2017;18:2622-34. 
112. Zhou J, Wang J, Hong B, Ma K, Xie H, Li L, Zhang K, Zhou B, Cai L, Gong $\mathrm{K}$. Gene signatures and prognostic values of $\mathrm{m} 6 \mathrm{~A}$ regulators in clear cell renal cell carcinoma-a retrospective study using TCGA database. Aging (Albany NY). 2019;11:1633-47.

113. Strick A, von Hagen F, Gundert L, Klümper N, Tolkach Y, Schmidt D, Kristiansen G, Toma M, Ritter M, Ellinger J. The N(6) -methyladenosine ( $\mathrm{m}(6)$ A) erasers alkylation repair homologue 5 (ALKBH5) and fat mass and obesity-associated protein (FTO) are prognostic biomarkers in patients with clear cell renal carcinoma. BJU Int. 2020:125:617-24.

114. Wang Q, Zhang H, Chen Q, Wan Z, Gao X, Qian W. Identification of METTL14 in kidney renal clear cell carcinoma using bioinformatics analysis. Dis Mark. 2019;2019:5648783.

115. Gong D, Zhang J, Chen Y, Xu Y, Ma J, Hu G, Huang Y, Zheng J, Zhai W, Xue W. The m(6)A-suppressed P2RX6 activation promotes renal cancer cells migration and invasion through ATP-induced $\mathrm{Ca}(2+)$ influx modulating ERK1/2 phosphorylation and MMP9 signaling pathway. J Exp Clin Cancer Res. 2019;38:233.

116. Liu T, Wang H, Fu Z, Wang Z, Wang J, Gan X, Wang A, Wang L. Methyltransferase-like 14 suppresses growth and metastasis of renal cell carcinoma by decreasing long noncoding RNA NEAT1. Cancer Sci 2021.

117. Wang Y, Cong R, Liu S, Zhu B, Wang X, Xing Q. Decreased expression of METTL14 predicts poor prognosis and construction of a prognostic signature for clear cell renal cell carcinoma. Cancer Cell Int. 2021;21:46

118. Wang S, Zou X, Chen Y, Cho WC, Zhou X. Effect of N6-methyladenosine regulators on progression and prognosis of triple-negative breast cancer. Front Genet. 2020;11:580036.

119. Chen J, Yu K, Zhong G, Shen W. Identification of a m(6)A RNA methylation regulators-based signature for predicting the prognosis of clear cell renal carcinoma. Cancer Cell Int. 2020;20:157.

120. Wei J, Qian Y, Tang Y, Ge X, Jiang K, Fang Y, Fu D, Kong X, Xiao Q, Ding K. Establishment of a risk signature based on m6A RNA methylation regulators that predicts poor prognosis in renal cell carcinoma. Onco Targets Ther. 2021;14:413-26.

121. Liu X, Wang P, Teng X, Zhang Z, Song S. Comprehensive analysis of expression regulation for RNA m6A regulators with clinical significance in human cancers. Front Oncol. 2021;11:624395.

122. Zhang $C$, Chen L, Liu Y, Huang J, Liu A, Xu Y, Shen Y, He H, Xu D. Downregulated METTL14 accumulates BPTF that reinforces super-enhancers and distal lung metastasis via glycolytic reprogramming in renal cell carcinoma. Theranostics. 2021;11:3676-93.

123. Wang X, Fu X, Zhang J, Xiong C, Zhang S, Lv Y. Identification and validation of m(6)A RNA methylation regulators with clinical prognostic value in Papillary thyroid cancer. Cancer Cell Int. 2020;20:203.

124. Zhang X, Li D, Jia C, Cai H, Lv Z, Wu B. METTL14 promotes tumorigenesis by regulating IncRNA OIP5-AS1/miR-98/ADAMTS8 signaling in papillary thyroid cancer. Cell Death Dis. 2021;12:617.

125. Li Z, Weng H, Su R, Weng X, Zuo Z, Li C, Huang H, Nachtergaele S, Dong L, Hu C, et al. FTO plays an oncogenic role in acute myeloid leukemia as a N(6)-methyladenosine RNA demethylase. Cancer Cell. 2017;31:127-41

126. Vu LP, Pickering BF, Cheng Y, Zaccara S, Nguyen D, Minuesa G, Chou T, Chow A, Saletore Y, MacKay M, et al. The N(6)-methyladenosine ( $\mathrm{m}(6)$ A)-forming enzyme METTL3 controls myeloid differentiation of normal hematopoietic and leukemia cells. Nat Med. 2017;23:1369-76.

127. Sun C, Chang L, Liu C, Chen X, Zhu X. The study of METTL 3 and METTL14 expressions in childhood ETV6/RUNX1-positive acute lymphoblastic leukemia. Mol Genet Genom Med. 2019;7:e00933.

128. Luo A, Yang L, Li M, Cai M, Huang A, Liu X, Yang X, Yan Y, Wang X, Wu X, et al. Genetic variants in METTL 14 are associated with the risk of acute lymphoblastic leukemia in Southern Chinese children: a five-center case-control study. Cancer Manag Res. 2021;13:9189-200.

129. Mao J, Qiu H, Guo L. LnCRNA HCG11 mediated by METTL14 inhibits the growth of lung adenocarcinoma via IGF2BP2/LATS1. Biochem Biophys Res Commun. 2021;580:74-80.

130. Wu Q, Xie X, Huang Y, Meng S, Li Y, Wang H, Hu Y. N6-methyladenosine RNA methylation regulators contribute to the progression of prostate cancer. J Cancer. 2021;12:682-92.

131. Zhao H, Xu Y, Xie Y, Zhang L, Gao M, Li S, Wang F. m6A regulators is differently expressed and correlated with immune response of esophageal cancer. Front Cell Dev Biol. 2021;9:650023.
132. Zhang C, Zhang M, Ge S, Huang W, Lin X, Gao J, Gong J, Shen L. Reduced m6A modification predicts malignant phenotypes and augmented Wnt/PI3K-Akt signaling in gastric cancer. Cancer Med. 2019;8:4766-81.

133. Li J, Rao B, Yang J, Liu L, Huang M, Liu X, Cui G, Li C, Han Q, Yang $H$, et al. Dysregulated m6A-related regulators are associated with tumor metastasis and poor prognosis in osteosarcoma. Front Oncol. 2020;10:769.

134. Zhuo Z, Hua RX, Zhang H, Lin H, Fu W, Zhu J, Cheng J, Zhang J, Li S, Zhou $\mathrm{H}$, et al. METTL14 gene polymorphisms decrease Wilms tumor susceptibility in Chinese children. BMC Cancer. 2021;21:1294.

135. Wang F, Zhu Y, Cai H, Liang J, Wang W, Liao Y, Zhang Y, Wang C, Hou J. N6-methyladenosine methyltransferase METTL14-mediated autophagy in malignant development of oral squamous cell carcinoma. Front Oncol. 2021;11:738406.

136. Wang M, Liu J, Zhao Y, He R, Xu X, Guo X, Li X, Xu S, Miao J, Guo J, et al. Upregulation of METTL14 mediates the elevation of PERP MRNA $N(6)$ adenosine methylation promoting the growth and metastasis of pancreatic cancer. Mol Cancer. 2020;19:130.

137. Chen S, Yang C, Wang ZW, Hu JF, Pan JJ, Liao CY, Zhang JQ, Chen JZ, Huang $Y$, Huang $L$, et al. CLK1/SRSF5 pathway induces aberrant exon skipping of METTL14 and Cyclin L2 and promotes growth and metastasis of pancreatic cancer. J Hematol Oncol. 2021;14:60.

138. Yi D, Wang R, Shi $X, X u L$, Yilihamu Y, Sang J. METTL 14 promotes the migration and invasion of breast cancer cells by modulating N6-methyladenosine and hsa-miR-146a-5p expression. Oncol Rep. 2020;43:1375-86

139. Sun T, Wu Z, Wang X, Wang Y, Hu X, Qin W, Lu S, Xu D, Wu Y, Chen $Q$, et al. LNC942 promoting METTL14-mediated m(6)A methylation in breast cancer cell proliferation and progression. Oncogene. 2020;39:5358-72.

140. Peng F, Xu J, Cui B, Liang Q, Zeng S, He B, Zou H, Li M, Zhao H, Meng $Y$, et al. Oncogenic AURKA-enhanced N(6)-methyladenosine modification increases DROSHA mRNA stability to transactivate STC1 in breast cancer stem-like cells. Cell Res. 2021;31:345-61.

141. Xiao H, Fan X, Zhang R, Wu G. Upregulated N6-methyladenosine RNA in peripheral blood: potential diagnostic biomarker for breast cancer. Cancer Res Treat. 2021;53:399-408.

142. Zhao X, Cui L. Development and validation of a m(6)A RNA methylation regulators-based signature for predicting the prognosis of head and neck squamous cell carcinoma. Am J Cancer Res. 2019:9:2156-69.

143. Martin GH, Park CY. Meddling with METTLs in normal and leukemia stem cells. Cell Stem Cell. 2018;22:139-41.

144. Wang Y, Li Y, Yue M, Wang J, Kumar S, Wechsler-Reya RJ, Zhang Z, Ogawa Y, Kellis M, Duester G, Zhao JC. N(6)-methyladenosine RNA modification regulates embryonic neural stem cell self-renewal through histone modifications. Nat Neurosci. 2018;21:195-206.

145. Wang Z, Pan Z, Adhikari S, Harada BT, Shen L, Yuan W, Abeywardana T, Al-Hadid Q, Stark JM, He C, et al. m(6) A deposition is regulated by PRMT1-mediated arginine methylation of METTL14 in its disordered C-terminal region. Embo j. 2021;40:e106309.

146. Galardi S, Michienzi A, Ciafrè SA: Insights into the regulatory role of $\mathrm{m}(6)$ A epitranscriptome in glioblastoma. Int J Mol Sci 2020, 21.

147. Huang $\mathrm{H}$, Weng $\mathrm{H}$, Zhou K, Wu T, Zhao BS, Sun M, Chen Z, Deng X, Xiao $G$, Auer F, et al. Histone H3 trimethylation at lysine 36 guides m(6)A RNA modification co-transcriptionally. Nature. 2019;567:414-9.

148. Ribas A, Wolchok JD. Cancer immunotherapy using checkpoint blockade. Science. 2018;359:1350-5.

149. Han D, Liu J, Chen C, Dong L, Liu Y, Chang R, Huang X, Liu Y, Wang J, Dougherty U, et al. Anti-tumour immunity controlled through mRNA m(6)A methylation and YTHDF1 in dendritic cells. Nature. 2019;566:270-4.

150. Wang L, Hui H, Agrawal K, Kang Y, Li N, Tang R, Yuan J, Rana TM. m(6) A RNA methyltransferases METTL3/14 regulate immune responses to anti-PD-1 therapy. Embo J. 2020;39:e104514.

151. Zhang N, Zuo Y, Peng Y, Zuo L. Function of N6-methyladenosine modification in tumors. J Oncol. 2021;2021:6461552.

152. Huang ME, Ye YC, Chen SR, Chai JR, Lu JX, Zhoa L, Gu LJ, Wang ZY. Use of all-trans retinoic acid in the treatment of acute promyelocytic leukemia. Blood. 1988:72:567-72. 
153. Choi KD, Vodyanik M, Slukvin II. Hematopoietic differentiation and production of mature myeloid cells from human pluripotent stem cells. Nat Protoc. 2011;6:296-313.

154. Zeng C, Wang W, Yu X, Yang L, Chen S, Li Y. Pathways related to PMAdifferentiated THP1 human monocytic leukemia cells revealed by RNA-Seq. Sci China Life Sci. 2015;58:1282-7.

155. Chim CS, Kwong YL, Liang R, Chu YC, Chan CH, Chan LC, Wong KF, Chan TK. All-trans retinoic acid (ATRA) in the treatment of acute promyelocytic leukemia (APL). Hematol Oncol. 1996;14:147-54.

156. Kumar S, Nagpal R, Kumar A, Ashraf MU, Bae YS. Immunotherapeutic potential of m6A-modifiers and MicroRNAs in controlling acute myeloid leukaemia. Biomedicines 2021, 9.

157. Kong F, Liu X, Zhou Y, Hou X, He J, Li Q, Miao X, Yang L. Downregulation of METTL14 increases apoptosis and autophagy induced by cisplatin in pancreatic cancer cells. Int J Biochem Cell Biol. 2020;122:105731.

158. Zhang C, Ou S, Zhou Y, Liu P, Zhang P, Li Z, Xu R, Li Y. m(6)A Methyltransferase METTL14-mediated upregulation of cytidine deaminase promoting gemcitabine resistance in pancreatic cancer. Front Oncol. 2021;11:696371

159. Yang Z, Yang S, Cui YH, Wei J, Shah P, Park G, Cui X, He C, He YY. METTL14 facilitates global genome repair and suppresses skin tumorigenesis. Proc Natl Acad Sci USA 2021, 118.

160. Roignant JY, Soller M. m(6)A in mRNA: an ancient mechanism for finetuning gene expression. Trends Genet. 2017;33:380-90.

161. Barski A, Cuddapah S, Cui K, Roh TY, Schones DE, Wang Z, Wei G, Chepelev I, Zhao K. High-resolution profiling of histone methylations in the human genome. Cell. 2007;129:823-37.

162. Litt MD, Simpson M, Gaszner M, Allis CD, Felsenfeld G. Correlation between histone lysine methylation and developmental changes at the chicken beta-globin locus. Science. 2001;293:2453-5.

163. Noma K, Allis CD, Grewal SI. Transitions in distinct histone H3 methylation patterns at the heterochromatin domain boundaries. Science. 2001:293:1150-5.

164. Meyer KD, Saletore Y, Zumbo P, Elemento O, Mason CE, Jaffrey SR. Comprehensive analysis of mRNA methylation reveals enrichment in $3^{\prime} U T R s$ and near stop codons. Cell. 2012;149:1635-46.

165. Fu Y, Dominissini D, Rechavi G, He C. Gene expression regulation mediated through reversible $\mathrm{m}^{6} \mathrm{~A}$ RNA methylation. Nat Rev Genet. 2014;15:293-306.

166. Winkler R, Gillis E, Lasman L, Safra M, Geula S, Soyris C, Nachshon A, Tai-Schmiedel J, Friedman N, Le-Trilling VTK, et al. m(6)A modification controls the innate immune response to infection by targeting type I interferons. Nat Immunol. 2019;20:173-82.

167. Engel M, Eggert C, Kaplick PM, Eder M, Röh S, Tietze L, Namendorf C Arloth J, Weber P, Rex-Haffner M, et al. The Role of m(6)A/m-RNA methylation in stress response regulation. Neuron. 2018;99:389-403.e389.

168. Xiang Y, Laurent B, Hsu CH, Nachtergaele S, Lu Z, Sheng W, Xu C, Chen $H$, Ouyang J, Wang S, et al. RNA m(6)A methylation regulates the ultraviolet-induced DNA damage response. Nature. 2017;543:573-6.

169. Liu P, Li F, Lin J, Fukumoto T, Nacarelli T, Hao X, Kossenkov AV, Simon MC, Zhang R. m(6)A-independent genome-wide METTL3 and METTL14 redistribution drives the senescence-associated secretory phenotype. Nat Cell Biol. 2021:23:355-65.

170. Liu X, Qin J, Gao T, Li C, Chen X, Zeng K, Xu M, He B, Pan B, Xu X, et al. Analysis of METTL3 and METTL14 in hepatocellular carcinoma. Aging (Albany NY). 2020;12:21638-59.

\section{Publisher's Note}

Springer Nature remains neutral with regard to jurisdictional claims in published maps and institutional affiliations.

Ready to submit your research? Choose BMC and benefit from:

- fast, convenient online submission

- thorough peer review by experienced researchers in your field

- rapid publication on acceptance

- support for research data, including large and complex data types

- gold Open Access which fosters wider collaboration and increased citations

- maximum visibility for your research: over $100 \mathrm{M}$ website views per year

At BMC, research is always in progress.

Learn more biomedcentral.com/submissions 